\title{
Transsynaptic Tracing with Vesicular Stomatitis Virus Reveals Novel Retinal Circuitry
}

\author{
Kevin T. Beier, ${ }^{1}$ Bart G. Borghuis, ${ }^{3}$ Rana N. El-Danaf, ${ }^{5,6,7}$ Andrew D. Huberman, ${ }^{5,6,7}$ Jonathan B. Demb, ${ }^{3,4}$ \\ and Constance L. Cepko ${ }^{1,2}$ \\ Departments of ${ }^{1}$ Genetics and ${ }^{2}$ Ophthalmology, Howard Hughes Medical Institute, Harvard Medical School, Boston, Massachusetts 02115, Departments of \\ ${ }^{3}$ Ophthalmology and Visual Science and ${ }^{4}$ Cellular and Molecular Physiology, Yale University School of Medicine, New Haven, Connecticut 06510, and \\ Departments of ${ }^{5}$ Neurosciences, ${ }^{6}$ Ophthalmology, and ${ }^{7}$ Neurobiology Section in the Division of Biology, University of California, San Diego, La Jolla, \\ California 92093
}

The use of neurotropic viruses as transsynaptic tracers was first described in the 1960 s, but only recently have such viruses gained popularity as a method for labeling neural circuits. The development of retrograde monosynaptic tracing vectors has enabled visualization of the presynaptic sources onto defined sets of postsynaptic neurons. Here, we describe the first application of a novel viral tracer, based on vesicular stomatitis virus (VSV), which directs retrograde transsynaptic viral spread between defined cell types. We use this virus in the mouse retina to show connectivity between starburst amacrine cells (SACs) and their known synaptic partners, directionselective retinal ganglion cells, as well as to discover previously unknown connectivity between SACs and other retinal ganglion cell types. These novel connections were confirmed using physiological recordings. VSV transsynaptic tracing enables cell type-specific dissection of neural circuitry and can reveal synaptic relationships among neurons that are otherwise obscured due to the complexity and density of neuropil.

\section{Introduction}

A major goal of neuroscience is to define the patterns of connections among specific types of neurons, and to understand how those connections support proper nervous system function. Neurotropic viruses such as pseudorabies (PRV) and rabies virus (RABV) can transmit between synaptically connected neurons and have been used to define neuronal connections. Callaway and colleagues (Wickersham et al., 2007) recently developed a modified RABV for monosynaptic retrograde tracing. RABV virions pseudotyped with a chimeric glycoprotein, composed of the extracellular domain of the ASLV EnvA protein and the cytoplasmic domain of the RABV G protein (A/RG) can only infect cells expressing the avian receptor, TVA. To direct infection of RABV (A/RG) to cells that express TVA, the gene encoding TVA can be delivered by transfection (Wickersham et al., 2007; Marshel et al., 2010), infection with a different virus (Wall et al., 2010; Miyamichi et al., 2011; Yonehara et al., 2011), or by use of TVA transgenic mice (Seidler et al., 2008; Beier et al., 2011a). Following RABV

Received Jan. 17, 2012; revised Sept. 13, 2012; accepted 0ct. 1, 2012.

Author contributions: K.T.B., A.D.H., B.G.B., J.B.D., and C.L.C. designed research; K.T.B., B.G.B., and R.N.E.-D. performed research; K.T.B., A.D.H., J.B.D., and C.L.C. contributed unpublished reagents/analytic tools; K.T.B., B.G.B., R.N.E.-D., A.D.H., J.B.D., and C.L.C. analyzed data; K.T.B., B.G.B., A.D.H., J.B.D., and C.L.C. wrote the paper.

This work was supported by the Howard Hughes Medical Institute (C.L.C.), National Institutes of Health (NIH) Grant NS068012-01 (K.T.B.), NIH Grant R01 EY014454 (J.B.D.), NIH Grant R01 EY022157-01 (A.D.H.), an Early Career Award from The Ziegler Foundation for the Blind (A.D.H.), and a grant from the Glaucoma Research Foundation Catalyst for a Cure Initiative (A.D.H.). We thank Phong Nguyen and Didem Goz for expert technical assistance, John Aach for statistical advice, and Wei Wei and Marla Feller for thoughtful discussions.

Correspondence should be addressed to Constance L. Cepko at the above address. E-mail: cepko@genetics.med.harvard.edu.

DOI:10.1523/JNEUROSCI.0245-12.2013

Copyright $\odot 2013$ the authors $\quad 0270-6474 / 13 / 330035-17 \$ 15.00 / 0$ infection of a TVA-expressing neuron, the RABV can transmit to other synaptically connected cells in a retrograde direction, even though those neurons do not express TVA (see Fig. 1A).

Here, we describe a new viral tracing system that uses several modifications of this RABV strategy. First, we used a recombinant vesicular stomatitis virus (rVSV), a virus related to RABV (Knipe, 2007), which we have shown can travel transsynaptically (Beier et al., 2011b). Second, we constructed a replicationcompetent rVSV to encode the A/RG chimeric glycoprotein to allow transmission from an initially infected cell only to cells that express TVA. Third, in the envelope of this virus (but not in its genome) we provided the nonchimeric RABV G-protein using a pseudotyping strategy, which allowed the initial inoculum to infect non-TVA-expressing cells. This allows one to choose a site for inoculation where TVA is not expressed, and then map connections only to neurons that express TVA.

The retina is perhaps the best understood structure in the mammalian CNS. Its input and output have been studied for many decades. However, many computations performed by the retina are still poorly understood, and only a small number of retinal microcircuits have been defined. These include the rod photoreceptor $\rightarrow$ rod bipolar $\rightarrow$ AII amacrine $\rightarrow$ cone bipolar $\rightarrow$ retinal ganglion cell (RGC) pathway (Kolb and Famiglietti, 1974; Demb and Singer, 2012), and the direction-selective (DS) circuit, comprising starburst amacrine cells (SACs) and directionselective retinal ganglion cells (DSGCs) (Demb, 2007). The working model for the DS circuit is relatively simple: the SACs provide DS inhibition onto the DSGCs. In addition, SACs generate waves of activity during an early developmental period, before vision is established; these waves contribute to retinotopic and eye- 
specific refinement of RGC axons in the brain (Feller et al., 1996; Huberman et al., 2008). Despite ongoing and intense study of SACs, many questions remain about their connections. The VSV tracing technique described here reveals novel connectivity patterns between SACs and their postsynaptic partners, the RGCs, and thereby raises several new hypotheses about the range and specificity of SAC roles in visual system function and assembly.

\section{Materials and Methods}

\section{Viral construction and preparation}

Viruses were constructed and rescued using standard methods (Whelan et al., 1995). The A/RG chimeric glycoprotein was cloned from pCMMP EnvARGCD IRES GFP (gift from Ian Wickersham, Massachusetts Institute of Technology, Boston, MA) into the G locus of the $\operatorname{rVSV}(\Delta \mathrm{G}) \mathrm{GFP}$ backbone using the NotI restriction site (Chandran et al., 2005).

To pseudotype $\mathrm{rVSV}(\mathrm{A} / \mathrm{RG}$ ) with RABV G, four $10 \mathrm{~cm}$ dishes of $90 \%$ confluent 293T TVA800 cells (gift from John Young, Salk Institute, La Jolla, CA) (Narayan et al., 2003) were each transfected with $5 \mu$ g of pCAG RABV G (gift from Ed Callaway, Salk Institute, La Jolla, CA). The subsequent day, these plates were infected at a multiplicity of infection of 0.01 with $\operatorname{rVSV}(\mathrm{A} / \mathrm{RG})$. Supernatants were collected every day for $4 \mathrm{~d}$ after infection, ultracentrifuged at 21,000 rpm for $90 \mathrm{~min}$, resuspended in 30 $\mu \mathrm{l}$ of DMEM, and frozen at $-80^{\circ} \mathrm{C}$. Viral stocks were titered on $293 \mathrm{~T}$ cells. Viral focus-forming units (ffu) were calculated 2 days postinfection (dpi) by identifying GFP-expressing cells, and the viral titer (focus-forming units per milliliter) was determined by performing a dilution series.

\section{$r V S V(A / R G)$ infection specificity for TVA-expressing cells}

To test rVSV(A/RG)infection specificity, relative viral infectivity of TVAexpressing and non-TVA-expressing tissue culture cells was quantified. A virus preparation of $\mathrm{rVSV}(\mathrm{A} / \mathrm{RG})$ was serially diluted onto five different cell lines: two that expressed the TVA receptor, including 293T TVA800 and mouse embryonic fibroblasts with both the cTVA and Cre alleles $(\mathrm{MEF}+/+)$ (Beier et al., 2011a), and three that did not express TVA, including NIH 3T3, 293T, and MEF+/- (with the cTVA but not the Cre allele) (Beier et al., 2011a). Fluorescent foci were quantified, and the ratio of infection relative to 293 T TVA800 cells was quantified.

\section{Mouse lines}

cTVA and Cre mice were genotyped using ubiquitin-C promoter and Cre coding sequence-specific primers, respectively, as described previously (Beier et al., 2011a). The cR26TdT [B6.Cg-Gt(ROSA)26Sor < tm9(CAGtdTomato)Hze $>/ \mathrm{J}$ ] (Madisen et al., 2010) and ChAT-Cre (The Jackson Laboratory; strain B6;129S6-Chat ${ }^{\mathrm{tm} 1(\mathrm{cre}) \text { Lowl } / \mathrm{J})}$ lines were obtained from The Jackson Laboratory. The Parvalbumin-Cre [B6;129P2$\mathrm{Pvalb}<\mathrm{tm} 1$ (cre)Arbr $>/ \mathrm{J}$ ] and channelrhodopsin-2-YFP [channelrhodopsin-2

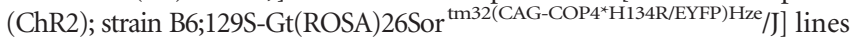
were also obtained from The Jackson Laboratory (Hippenmeyer et al., 2005). The VGlut3-Cre mouse line, a BAC transgenic animal with Cre in the coding region, was a generous gift from Botond Roska (Friedrich Miescher Institute, Basel, Switzerland). The $\beta$-actin Cre strain was a generous gift from Susan Dymecki.

DRD4-EGFP, CB2-GFP, and Cdh3-GFP transgenic mouse lines were obtained from the MMRRC GENSAT collection (Gong et al., 2003) and crossed with $\mathrm{C} 57 \mathrm{BL} / 6$ mice or maintained on a mixed pigmented background. DRD4-GFP mice express GFP in one subtype of DSGC (Huberman et al., 2009), Cdh3-GFP mice express GFP in two to three subtypes of RGCs that project to non-image-forming visual nuclei (Osterhout et al., 2011), and CB2-GFP mice express GFP in transient Off- $\alpha$-RGCs (Huberman et al., 2008).

\section{Virus injections}

For caudate-putamen (CP) injections, $100 \mathrm{nl}$ of $1 \times 10^{9} \mathrm{ffu} / \mathrm{ml} \mathrm{rVSV}(\mathrm{A} /$ $\mathrm{RG}$ ) pseudotyped with RABV G was injected into cTVA/cR26TdT/PVCre triple-transgenic mice between 5 and 8 weeks of age, or cTVA/ cR26TdT/VGlut3-Cre transgenic mice. Mice were perfused 3 dpi. For animals injected with Adenovirus-Cre (Baylor College of Medicine Vector Core), $\mathrm{rVSV}(\mathrm{A} / \mathrm{RG}$ ) pseudotyped with RABV G was injected into the left hemisphere of the motor cortex of cTVA/cR26TdT transgenic mice, while $100 \mathrm{nl}$ of $1 \times 10^{10} \mathrm{cfu} / \mathrm{ml}$ Adenovirus-Cre was injected into the equivalent coordinates of the opposite hemisphere at the same time. Mice were perfused 3 dpi.

For lateral geniculate nucleus (LGN) injections, animals were injected with $250 \mathrm{nl}$ of $\mathrm{rVSV}(\mathrm{A} / \mathrm{RG})$ pseudotyped with RABV G, and perfused between 2 and 7 dpi.

Transgenic mice of either sex were used throughout.

Injection coordinates used were as follows: LGN: A/P -2.46 from bregma, L/M 2, D/V - 2.75; CP: A/P + 1 from bregma, L/M 1.8, D/V -2.5 ; motor cortex: $\mathrm{A} / \mathrm{P}+1.34$ from bregma, $\mathrm{L} / \mathrm{M} 1.7, \mathrm{D} / \mathrm{V}-0.75$.

For analyses of RGCs, 42 retinas were used from mice injected into the LGN. This resulted in sparse labeling of RGCs (see Fig. 4A), generally permitting unambiguous analysis of single RGCs. Only labeled RGCs without overlapping dendritic arbors with other labeled RGCs were used for analysis. Figure 5, $E$ and $F$, includes tables of these data.

\section{Histology}

Mice were perfused with saline followed by $4 \%$ formaldehyde in PBS, and their eyes were removed whole and postfixed for $4 \mathrm{~h}$ in $4 \%$ formaldehyde in PBS at $4^{\circ} \mathrm{C}$. The cornea and lens were removed and the eyecup cryoprotected in 30\% sucrose, before embedding in 2:1 sucrose/OCT for cryosectioning. Sections were cut at $14 \mu \mathrm{m}$ and thaw mounted onto slides. Primary antibodies used were as follows: rabbit anti-GFP and guinea pig anti-VAChT.

Brain tissue was perfused and then postfixed overnight in $4 \%$ formaldehyde in PBS, transferred to $30 \%$ sucrose, allowed to sink, and sectioned at $40 \mu \mathrm{m}$ on a freezing sliding microtome.

Polar plots to analyze the relative positions of DSGCs and SACs were created using MATLAB software.

\section{Targeted filling of genetically labeled RGCs and analysis of} costratification with cholinergic laminae

Retinas from age P25-P60 mice were dissected and kept in an oxygenated $\left(95 \% \mathrm{O}_{2} / 5 \% \mathrm{CO}_{2}\right)$ solution of Ames' medium (Sigma-Aldrich) supplemented with $23 \mathrm{~mm} \mathrm{NaHCO}_{3}$. RGCs were visualized with differential interference contrast optics and epifluorescence to target $\mathrm{GFP}^{+}$somata and filled with borosilicate glass electrodes containing $10 \mathrm{~mm}$ solution of Alexa Fluor 555 hydrizide (Invitrogen) in $200 \mathrm{~mm} \mathrm{KCl}$. Hyperpolarizing current pulses ranging between 0.1 and $0.9 \mathrm{nA}$ were applied for 5-20 min to obtain the complete cell fill (evidenced by filled axon and fine processes and comparison with GFP).

After filling, retinas were fixed for $1 \mathrm{~h}$ with $4 \%$ formaldehyde, washed with $1 \times$ PBS for $1 \mathrm{~h}$, and incubated for $1 \mathrm{~h}$ in a blocking solution ( $10 \%$ goat serum, $0.25 \%$ Triton-X) at room temperature. The retinas were incubated overnight at $4^{\circ} \mathrm{C}$ with the following primary antibodies in blocking solution: rabbit anti-GFP (1:1000; Invitrogen) and guinea pig anti-VAChT (1:1000; Millipore). Sections were rinsed with PBS (three times, $30 \mathrm{~min}$ ), and incubated for $2 \mathrm{~h}$ at room temperatures with the following secondary antibodies: Alexa Fluor 488 goat anti-rabbit and Alexa Fluor 647 goat anti-guinea pig (1:1000; Invitrogen). Sections were rinsed with PBS and mounted with Prolong Gold with DAPI (Invitrogen).

Neurons were imaged using a $40 \times$ water-immersion objective lens on a Zeiss LSM 710 laser-scanning confocal microscope. Image stacks were collected at a scanning resolution of $1024 \times 1024$ pixels, and a step size through the $z$-axis of $0.5 \mu \mathrm{m}$.

\section{Retinal electrophysiology}

Recordings were made in whole-mount retinas from 3- to 6-week-old C57/B6 mice of either sex. The mice studied were the offspring of two transgenic lines: the ChAT-Cre line and a second line, in which expression of a channelrhodopsin-2-YFP fusion protein is Cre dependent. The offspring (ChAT-CRE/ChR2) expressed ChR2 selectively in SACs throughout the retina.

Retinas were prepared in accordance with protocols approved by Yale University and using standard methods published previously (Borghuis et al., 2011). Eyes were dissected in oxygenated Ames' medium (95\% $\mathrm{O}_{2} / 5 \% \mathrm{CO}_{2}$; Sigma-Aldrich). The retina was removed from the pigmented epithelium and placed in a perfusion chamber on 
an upright Olympus BX-51 microscope that was modified for twophoton fluorescence microscopy. Retinas were perfused with oxygenated Ames' medium at physiological temperature $\left(34-36^{\circ} \mathrm{C}\right)$ throughout the recordings. Two-photon fluorescence images were obtained with ScanImage software, version 3.6 (www.scanimage.org), using an Olympus $60 \times, 0.9 \mathrm{NA}$, LUMPlanFl/IR objective and an ultrafast pulsed laser (Chameleon Ultra II; Coherent) tuned to $910 \mathrm{~nm}$. ChR2 was activated with a high-power blue LED ( $\lambda_{\text {peak }}, 450 \mathrm{~nm}$; $1 \mathrm{~W}$ power corresponding to $3 \times$ $10{ }^{17}$ photons $\left.\cdot \mathrm{cm}^{-2} \cdot \mathrm{s}^{-1}\right)$ focused on the retina through the condenser lens of the microscope.

Intracellular solution for whole-cell patch-clamp recordings contained the following (in $\mathrm{mm}$ ): 120 Cs-methanesulfonate, 5 TEA-Cl, 10 HEPES, 10 BAPTA, $3 \mathrm{NaCl}, 2$ QX-314-Cl, 4 ATP-Mg, 0.4 GTP-Na ${ }_{2}$, and 10 phosphocreatine, pH 7.3, 280 mOsm; $10 \mu \mathrm{M}$ Alexa Fluor 568 (Invitrogen) was added to visualize the recorded cell. Currents were recorded with an Axon Multiclamp 700B amplifier controlled with PClamp 10 software (Molecular Devices). Data were analyzed with custom algorithms in MATLAB (MathWorks). To isolate GABAergic currents evoked by ChR2 activation, the following drugs were added to Ames' medium: $100 \mu \mathrm{m}$ DNQX (AMPA/kainate receptor antagonist), $100 \mu \mathrm{M}$ D-AP5 (NMDA receptor antagonist), $20 \mu \mathrm{m}$ L-AP4 (group III mGluR agonist), $1 \mu \mathrm{M}$ strychnine (glycine receptor antagonist), and $50 \mu \mathrm{M}$ tubocurarine (nicotinic acetylcholine receptor antagonist). GABAergic currents were then blocked by adding $50 \mu \mathrm{m}$ gabazine (SR-95531) $\left(\mathrm{GABA}_{\mathrm{A}}\right.$ receptor antagonist). To isolate cholinergic currents, the following drugs were added to Ames' medium: $100 \mu \mathrm{m}$ DNQX, $100 \mu \mathrm{M}$ D-AP5, $20 \mu \mathrm{M}$ $\mathrm{L}-\mathrm{AP} 4,1 \mu \mathrm{M}$ strychnine, and $50 \mu \mathrm{M}$ gabazine. Cholinergic currents were then blocked by adding either $50 \mu \mathrm{M}$ tubocurarine or $100 \mu \mathrm{M}$ hexamethonium. All of the above synaptic blockers were purchased from Tocris Bioscience (www.tocris.com). Responses evoked by ChR2 activation were quantified by averaging a leak-subtracted current over a $500 \mathrm{~ms}$ window. The leak current was measured over a time period just before the ChR2-activating stimulus. For ON- $\alpha$ cells, the response to the first light pulse on the first trial was excluded to avoid the melanopsinmediated response (see Results). In some cells, light-evoked responses were measured with intact synaptic function using a modified Dell projector described previously (Estevez et al., 2012).

Series resistance during the recording was $<30 \mathrm{M} \Omega$ and compensated by $50 \%$. Excitatory currents were recorded with a holding potential $\left(V_{\text {hold }}\right)$ at the calculated chloride reversal potential $\left(E_{\mathrm{Cl}}=-67 \mathrm{mV}\right)$; inhibitory currents were recorded at $V_{\text {hold }}=0 \mathrm{mV}$. Errors in the holding potential introduced by the uncompensated series resistance were corrected as described previously (Manookin et al., 2010).

All mouse work involving viruses was conducted in biosafety containment level 2 conditions, and all procedures were approved by the Harvard University Committee on Microbiological Safety and Harvard University, Yale University, and University of California San Diego Institutional Animal Care and Use Committees.

\section{Antibodies}

Primary antibodies. Primary antibodies were as follows: goat anti-choline acetyltransferase (Millipore; AB144P; 1:30), rabbit anti-tyrosine hydroxylase (Millipore; AB152; 1:500), chicken anti-GFP (Abcam; ab13970; 1:2000), rabbit anti-DsRed (tdTomato) (Clontech; 632496; 1:1000), rabbit anti-GFP (Invitrogen; 632375; 1:1000), guinea pig anti-VAChT (Millipore Bioscience Research Reagents; AB1588; 1:1000).

Secondary antibodies. Secondary antibodies were as follows: donkey anti-chicken Dylight 488 (Jackson ImmunoResearch; 1:250), donkey anti-rabbit Dylight 549 (Jackson ImmunoResearch; 1:250), donkey antirabbit Dylight 649 (Jackson ImmunoResearch; 1:250), donkey anti-goat Dylight 549 (Jackson ImmunoResearch; 1:250), donkey anti-goat Dylight 649 (Jackson ImmunoResearch; 1:250), goat anti-rabbit Alexa 488 highly cross-absorbed (Invitrogen; 1:1000), and goat anti-guinea pig Alexa 647 highly cross-absorbed (Invitrogen; 1:1000).

\section{Results}

Selective targeting of rVSV to TVA-expressing cells

Recently, we showed that the direction of viral spread by rVSV vectors is determined by the glycoprotein in the lipid envelope of the virus (Beier et al., 2011b). The glycoprotein of VSV with its own G-protein [VSV(VSV-G)] served as a model for early work on membrane proteins (Rodriguez Boulan and Pendergast, 1980). Its cytoplasmic domain was shown to direct its intracellular targeting to basolateral membranes (Thomas et al., 1993). In a similar fashion, the A/RG chimeric glycoprotein, which allows spread specifically to TVA-expressing cells, likely exhibits retrograde-specific spread due to the cytoplasmic domain of RABV G, as suggested by the fact that RABV normally spreads retrogradely via its own G-protein. We sought to determine whether this $\mathrm{A} / \mathrm{RG}$ glycoprotein would also mediate retrograde transmission when used with VSV. A rVSV was thus created that encoded the $\mathrm{A} / \mathrm{RG}$ chimeric glycoprotein in the viral genome $[\mathrm{rVSV}(\mathrm{A} / \mathrm{RG})]$. It was then tested for TVA specificity in vitro on five cell lines (see Materials and Methods). Infection of TVAexpressing cells relative to non-TVA-expressing cells was $\sim 10^{5}: 1$, as reported previously (Wickersham et al., 2010), indicating infection by this virus was TVA specific (data not shown).

To test for the transmission properties of this rVSV in vivo, a mouse that constitutively expresses TVA was created by crossing a strain with a conditional allele of TVA (Beier et al., 2011a) to the $\beta$-actin Cre strain (Lewandoski and Martin, 1997). In the progeny of this cross, we injected into the primary motor cortex the replication-competent $\mathrm{rVSV}(\mathrm{A} / \mathrm{RG})$. The virus did not label any anterograde projection nuclei. Rather, the virus spread only locally within the cortex, similar to results observed with a retrograde PRV strain (O'Donnell et al., 1997) (see Fig. 2A). The lack of labeling at longer distances likely reflects a lack of functional long-distance axonal transport of the virions with the A/RG chimeric glycoprotein.

To improve the long-range retrograde transport properties of this virus, a pseudotyping strategy was used. This strategy allowed observation of infected cells away from an injection site, by using the RABV G-protein to promote long-distance retrograde transport (Fig. $1 B, C$ ). rVSV with the A/RG chimeric glycoprotein encoded within its genome was grown in tissue culture cells, which transiently expressed RABV G supplied by a plasmid (i.e., RABV G was not encoded by the rVSV). To test whether this virus would retrogradely label cells away from an injection site, the CP was injected. This initially caused infection of layer 3 and layer 5 (L3 and L5) cortical pyramidal neurons (Fig. 2B), consistent with known projection patterns, in addition to contralaterally projecting L5 cortical pyramidal neurons (Kandel, 2000; Reiner et al., 2003). Infected cortical areas could then be examined for evidence of replication and local spread via the A/RG chimeric glycoprotein to cells expressing TVA. Local retrograde spread to interneurons was the predicted result. Indeed, such spread was seen in TVA-expressing mice, but not in TVA-negative mice (Fig. $2 B, C)$.

\section{Pseudotyping with RABV G can direct the microcircuit tracing virus to defined cell types}

The above strategy should allow interrogation of connectivity among specific types of neurons by (1) using specific Cre lines to create TVA-expressing cells, and by (2) injecting rVSV(A/RG) pseudotyped with RABV G to define the initially infected ("starter") population. To test this strategy, we used the Parvalbumin-Cre (PV-Cre) mouse line, in which Cre is expressed in large fast-spiking cortical interneurons (Hippenmeyer et al., 2005; Madisen et al., 2010; Wall et al., 2010). rVSV(A/RG) pseudotyped with RABV G was injected into the $\mathrm{CP}$ of a cTVA/cR26TdT/PV-Cre triple-transgenic mouse, where TVA and tdTomato are expressed in all cells with a Cre expression history. Consistent with the results shown in 
A

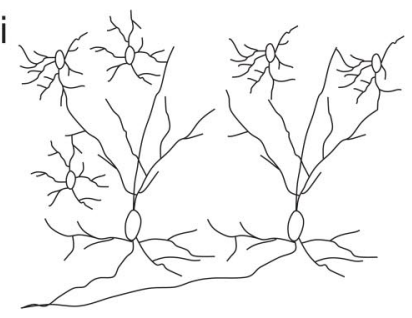

iv

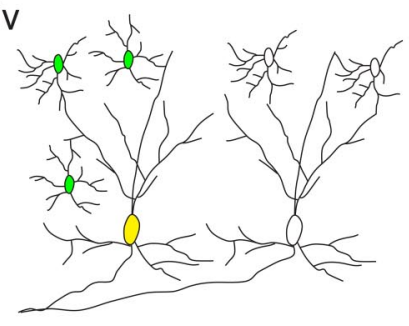

B
Transfect starter cell with 3 plasmids:

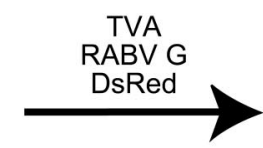

Wait for viral spread

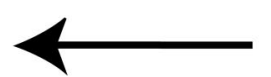

ii

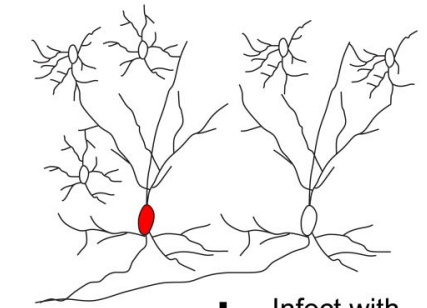

iii

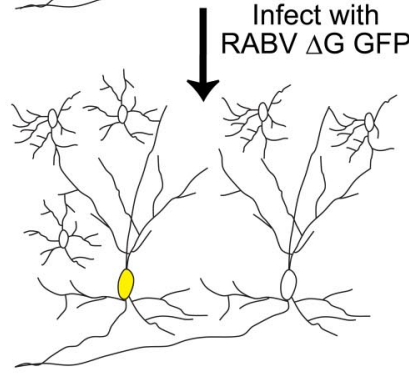

i
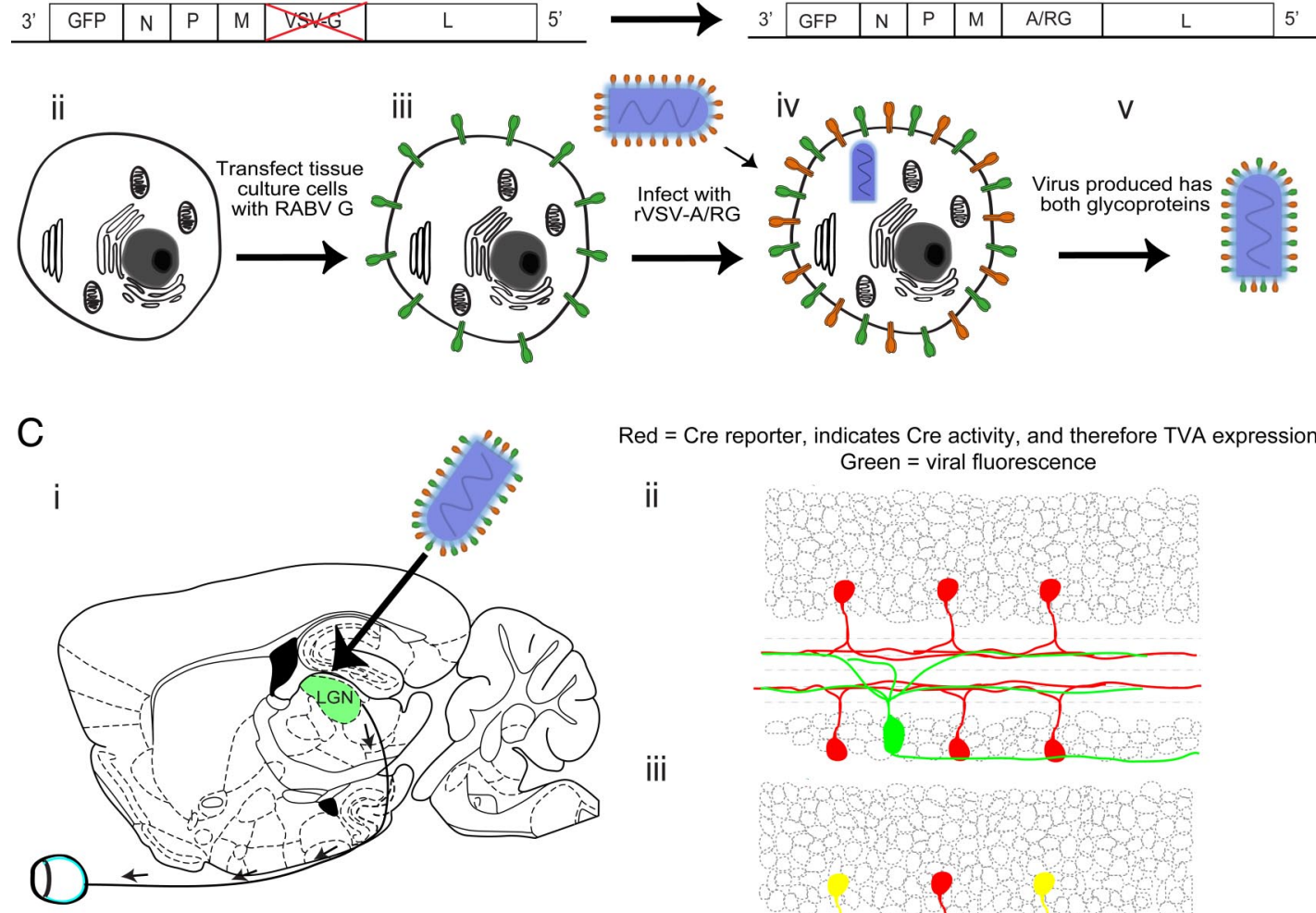

Red $=$ Cre reporter, indicates Cre activity, and therefore TVA expression

ii Green $=$ viral fluorescence

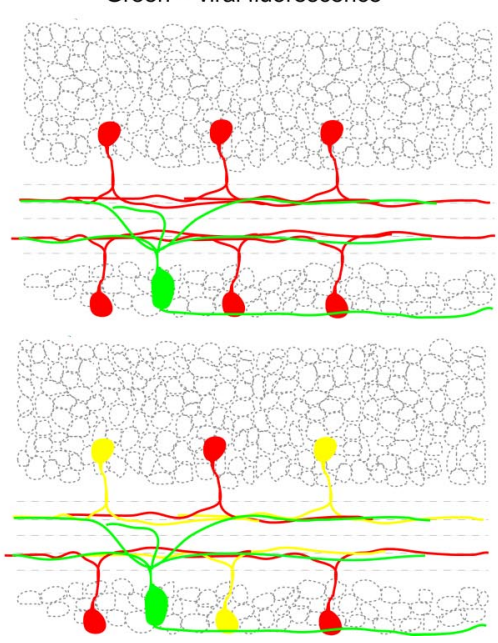

Figure 1. Schematics of viral tracing systems. A, Monosynaptic retrograde RABV tracing system, as developed by Wickersham et al. (2007). $i$, First, the TVA receptor, RABV G, and DsRed are transfected into a population of "starter cells" (red). ii, Then, the transfected region is infected with a GFP-expressing RABV pseudotyped with A/RG. (iii) Infected starter cells would therefore become yellow. iii, iv, The GFP-RABV then spreads from the starter cells (yellow) to nearby, retrogradely connected neurons (green) (iv). $\boldsymbol{B}$, The VSV pseudotyping strategy used throughout this study. $\boldsymbol{i}$, The recombinant VSV vectors have six genes, including GFP, and the VSV genes, N, P, M, G, and L. The VSV G gene was replaced with the gene encoding the A/RG chimeric glycoprotein (Wickersham et al., 2007). ii, To pseudotype rVSV(A/RG) with RABV G, tissue culture cells were first transfected with a plasmid encoding RABV G. iii, Once expressing RABV G, the cells were infected with the rVSV(A/RG) virus. iv, $\boldsymbol{v}$, The infected cells produce both the RABV G (green) and A/RG (orange) glycoproteins (iv), resulting in virions containing both glycoproteins in the viral envelope (v). C, The retrograde tracing method conducted in this study to analyze microcircuitry. $\boldsymbol{i}$, The presence of the RABV G-protein in the virion envelope permits retrograde transport. $\ddot{i}$, RGCs projecting to the $L G N$ would thus be labeled by an injection into the LGN (green). Once the virus enters a cell that has retrogradely taken up the virion, replication occurs, and virions are released. These virions can only infect TVA-expressing neurons (red), as the rVSV genome encodes only A/RG. These TVA-expressing cells are red as they have recombined a tdTomato reporter by Cre. The RABV G C-terminal domain present in the A/RG chimeric glycoprotein directs infectious particle release to the cell body and dendrites, causing the virus to transmit specifically to presynaptic neurons expressing TVA. iii, Cells infected by retrograde transmission following rVSV with A/RG production by RGCs will be yellow, as they will express GFP from viral infection as well as tdTomato. Cells that were infected by retrograde transport from the initial inoculum will only be green from GFP. 


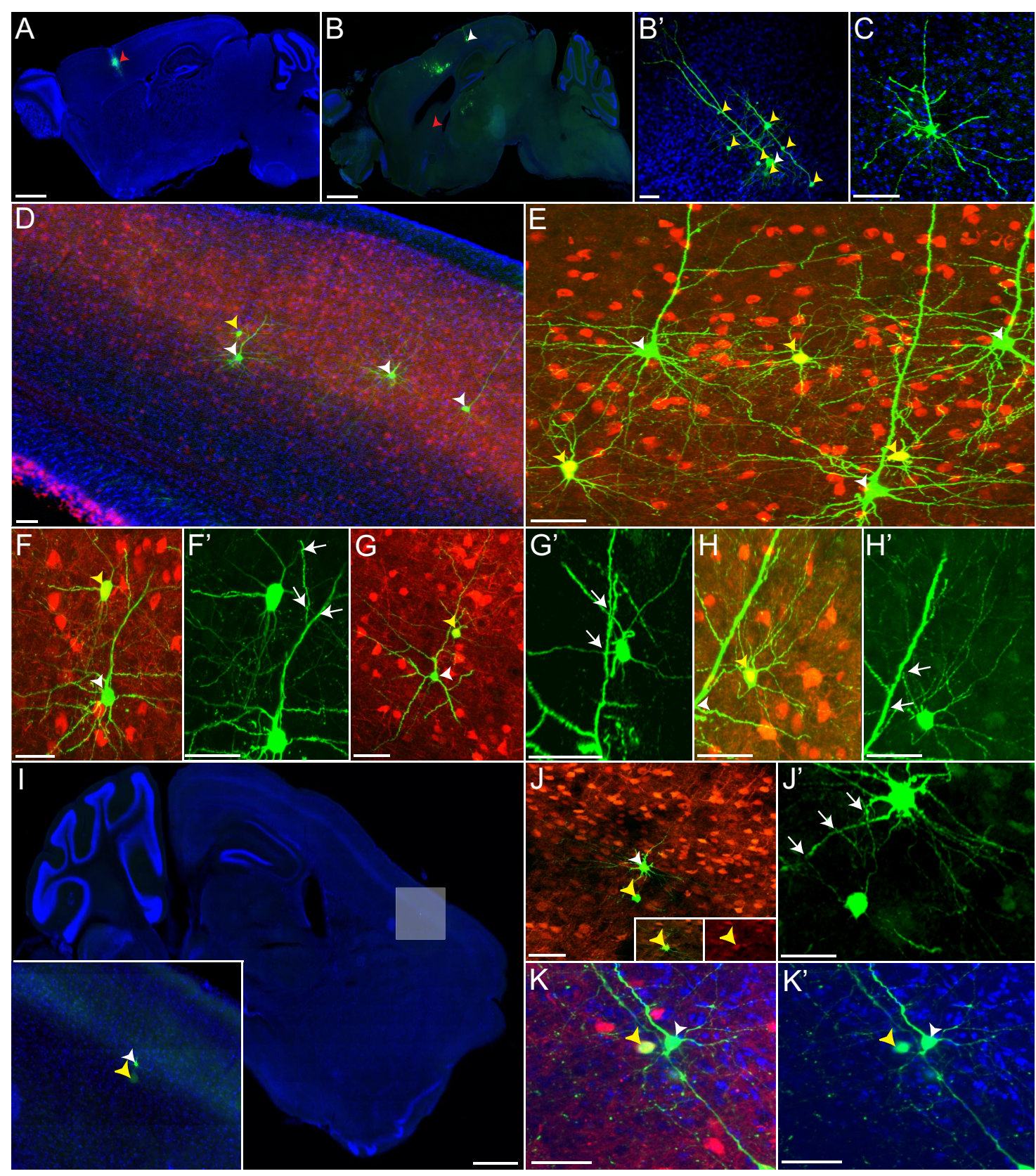

Figure 2. $\operatorname{rVSV(A/RG)~labels~local~microcircuitry~in~a~retrograde~direction~in~restricted~recipient~neuron~populations.~} A$, When rVSV(A/RG) was injected into the motor cortex of a mouse constitutively expressing TVA, by $3 \mathrm{dpi}$, local infection was observed at the injection site (red arrowhead), but no evidence of long-distance retrograde or anterograde transport was observed. $\boldsymbol{B}$, To test for neuron-to-neuron transmission properties, RABV G was used to pseudotype rVSV(A/RG) (as shown in Fig. $1 B$ ) to permit retrograde infection away from the injection site. In this case, the CP was injected (red arrowhead), permitting infection of ipsilateral L 3 and $L 5$ cortical pyramidal neurons (white arrowhead) and local spread from these cortical neurons. $\boldsymbol{B}^{\prime}, A$ higher magnification of the area marked by a white arrowhead in $\boldsymbol{B}$, with the white arrowhead showing a pyramidal neuron labeled by initial infection. The neurons likely infected by virus spread (yellow arrowheads) were near the dendrites of the pyramidal cell, consistent with retrograde viral transmission. C, No spread from projection neurons, here a L2/3 cortical pyramidal neuron, that were infected by the initial inoculum [rVSV(A/RG) pseudotyped with RABV G] was observed in animals not expressing TVA. $\boldsymbol{D}-\boldsymbol{H}$, rVSV(A/RG) pseudotyped with RABV G was injected into the (P of mice expressing TVA and tdTomato specifically in PV-Cre-expressing cells. At 3 dpi, L3 and L5 projection neurons ipsilaterally were infected by the initial inoculum. These neurons then produced rVSV(A/RG), which infected synaptically connected TVA-expressing upstream cells. $\boldsymbol{D}$, Initially infected ipsilateral $L 3$ pyramidal neurons (white arrowheads), with a single yellow local interneuron (yellow arrowhead). All cells that were not $\mathrm{L} 3$ or $\mathrm{L} 5$ projection neurons expressed tdTomato. $E$, High magnification of an infected region of the cortex, showing three local TVA-expressing interneurons (yellow arrowheads). These were infected by viral spread from initially infected pyramidal neurons (white arrowheads). $\boldsymbol{F}-\boldsymbol{H}$, Pairs of pyramidal and local interneurons, with the pyramidal neuron indicated by the white arrowheads, and interneuron by the yellow arrowheads. All yellow neurons were basket cells, which express PV. The single-neuron resolution permits visualization of the physical overlap between neurons (white arrows in $\boldsymbol{F}^{\prime}, \boldsymbol{G}^{\prime}, \boldsymbol{H}^{\prime}$ show examples of such overlaps). $\boldsymbol{I}, \boldsymbol{J}$, The viral titer can be adjusted to give single neuron resolution. When virus was injected into the (P of a VGlut3-Cre/cTVA/ CR26TdT mouse, only two labeled neurons were observed in this $100 \mu \mathrm{m}$ parasaggital section — a pyramidal neuron (white arrowhead), and a local TVA-expressing neuron to which the virus spread (yellow arrowhead) (I, inset). $J$, Higher magnification of the cells in $I$ (insets indicate that the cell to which the yellow arrowhead points is tdTomato + ), and $J^{\prime}$ indicates overlap of neuronal processes. $\boldsymbol{K}$, Adenovirus-Cre was injected into the motor cortex of a cTVA/cR26TdT mouse. rVSV(A/RG) pseudotyped with RABV G was injected into the same coordinates in the opposite hemisphere from the Adenovirus-Cre. At 3 dpi, projection neurons were initially infected by rVSV through retrograde uptake of virus. Interneurons that were infected with Adenovirus-Cre (tdTomato-positive cells) were occasionally infected (yellow cell, yellow arrowhead) by spread of rVSV(A/RG) from the projection neuron (green cell, white arrowhead). Green, viral fluorescence; red, tdTomato-based Cre reporter; blue, DAPI. Scale bars: $\boldsymbol{B}^{\prime}-\boldsymbol{H}, \boldsymbol{J}, \boldsymbol{K}, 50 \mu \mathrm{m} ; \boldsymbol{A}, \boldsymbol{B}, \boldsymbol{I}, 1 \mathrm{~mm}$. 
Figure $2 B$, the RABV G led to infection of cortical layers 3 and 5 (Kandel, 2000; Reiner et al., 2003). Each cell was green but not red, indicating that none of these RABV G-infected neurons had a PV-Cre expression history (Fig. 2D-H). After a survival period of $3 \mathrm{~d}$, yellow interneurons were observed near the dendrites of the initially infected $\mathrm{CP}$ projection neurons, indicating viral spread to TVA-expressing cells (Fig. 2D-H). The yellow cells were identified as basket cells (an interneuron type known to express parvalbumin), based on their location and morphology. In each case, cofasciculation of neuronal processes were observed among the yellow and green cells, indicating potential synaptic contacts (Chklovskii, 2004). The location of such contacts was always on the pyramidal neuron dendrites or cell body, which is consistent with the known subcellular targeting of parvalbumin basket cells onto pyramidal neurons. No virally infected chandelier cells (another parvalbumin-expressing interneuron population) were seen, potentially because these cells make contacts exclusively on the axon-initial segment of the pyramidal neurons and may therefore not be labeled by a transsynaptic retrograde tracer (Freund et al., 1983; Kawaguchi and Kubota, 1997).

These data demonstrate the effectiveness of a two-part strategy that uses rVSV to interrogate potential connections among specified neurons. A specific category of presynaptic partners is selectively made capable of receiving retrogradely transmitted virus through the use of Cre and a conditional allele of TVA. Only this population can be infected by the $\mathrm{rVSV}(\mathrm{A} / \mathrm{RG})$ virions produced by an initially infected, starter population of neurons. The starter neurons are defined by the choice of the injection site and the use of the RABV G-protein on the initial virion particles. RABV G allows infection of cells that do not necessarily express TVA at the injection site, as well as cells that project to the injection site, by virtue of the ability of RABV G to support long-range retrograde transport. The PV-Cre example in Figure 2 can be generalized to essentially any Cre mouse line. An additional example is provided by VGlut3-Cre, in which the connections from TVA-expressing cells to a projection-defined subpopulation were demonstrated (Fig. $2 I, J$ ). As an alternative, the Cre protein can be introduced into specific regions of the brain or body by viral transduction, such as by infection with an adenovirus expressing Cre, as was done successfully here by injecting Adenovirus-Cre into the motor cortex of the contralateral hemisphere (Fig. $2 \mathrm{~K}$ ).

\section{Unbiased exploration of connectivity patterns between SACs and RGCs}

The viral strategy described above was used to probe the connectivity between SACs and their postsynaptic partners: RGCs. A subset of RGCs is known to exhibit DS responses to visual stimuli (Barlow and Hill, 1963). Direction selectivity of these cells arises from input by SACs, a type of cholinergic/GABAergic interneuron (Euler et al., 2002; Lee et al., 2010) (for review, see Demb, 2007; Wei and Feller, 2011). SACs provide synaptic inhibition onto DSGCs, primarily on the null side of the DSGC, from which motion detection is suppressed (Fried et al., 2002; Lee et al., 2010; Briggman et al., 2011). The soma-dendrite vector of connected SACs most often point in the null direction of the DSGC (Briggman et al., 2011). The DSGCs that respond to both increments and decrements in light are called "ON-OFF-DSGCs." As DSGCs get robust inputs from SACs (Wei et al., 2011), a bona fide viral transsynaptic tracer ought to transmit retrogradely from $\mathrm{ON}$ OFF-DSGCs specifically to the connected SACs whose processes lie within the dendritic field of the RGC. An additional prediction is that the retrogradely labeled SACs would show an asymmetric distribution, to the null side of the DSGC dendritic arbor (Briggman et al., 2011). A nondirect synaptic relationship would be implied by spread of the virus from an ON-OFF-DSGC to SACs with nonoverlapping arbors and/or located randomly throughout the DSGC dendritic arbor.

SACs are generally believed to provide direct input only to DSGCs (Euler et al., 2002; Fried et al., 2005). It has not been thoroughly examined, however, whether SACs also provide synaptic input to non-DSGCs. The VSV tracing method provides a novel approach for exploring the question of SAC-to-non-DSGC connectivity. To label only RGCs with the initial infection, we injected the $\operatorname{rVSV}(\mathrm{A} / \mathrm{RG})$ virus pseudotyped with RABV G into the LGN. This should result in the random labeling of the many subtypes of RGCs that project to the LGN (Huberman et al., 2008, 2009; Kim et al., 2008; Siegert et al., 2009; Rivlin-Etzion et al., 2011). The dominant model of SAC connectivity would predict that, since only SACs are competent to be infected with rVSV transmitted retrogradely from RGCs in the ChAT-Cre/cTVA mouse, only ON-OFF-DSGCs and ON-DSGCs would transmit the virus transsynaptically to SACs (Lee and Zhou, 2006). This is because even though many or all types of LGN-projecting RGCs are infected with rVSV, only these RGC types have been shown to receive direct input from SACs.

As expected, a variety of morphologically distinct RGC types were labeled following injection of $\mathrm{rVSV}(\mathrm{A} / \mathrm{RG})$ virus pseudotyped with RABV G into the LGN. These included ONDSGCs, OFF-DSGCs (Kim et al., 2008), ON-OFF-DSGCs, putative edge detectors, $\mathrm{ON}-\alpha$, and OFF- $\alpha$-RGCs, as well as some types whose functional identities remain undefined (Figs. 3, $4 A-D, 5 A$ ) (Rockhill et al., 2002; Völgyi et al., 2009). We confirmed the specificity of transmission of $\operatorname{rVSV}(\mathrm{A} / \mathrm{RG}$ ) only to TVA-expressing cells by making injections into non-TVAexpressing mice that were transgenic for a conditional allele of TVA (cTVA) but that did not carry the Cre gene (i.e., cTVA+/ Cre-). At 4 dpi in these control mice, many GFP+ RGCs were observed, indicating they were infected, but no viral spread to other cell types was observed, as RGCs were the only cells labeled $(N=228$ RGCs $)$.

The ChAT-Cre/cTVA mouse was crossed to a mouse with a conditional allele of tdTomato to label the cells with a ChATCre history. ChAT cells also were defined by immunohistochemistry with anti-ChAT antisera, which defines their processes within the inner plexiform layer (IPL). The IPL is the laminated neuropil where amacrine cells, bipolar cells, and RGCs form synapses. Staining with ChAT antisera defines two laminae within the IPL, referred to as the ChAT bands or laminae, at the boundary of lamina 2 and 3 (OFF ChAT lamina) and at lamina 4 (ON ChAT lamina) (Fig. $4 H$ ). We injected the LGN of these mice with $\operatorname{rVSV}(\mathrm{A} / \mathrm{RG})$ pseudotyped with RABV G. As above, this resulted in the infection of a variety of RGCs. In addition, a limited number of infected SACs in the vicinity of the retrogradely infected RGCs was observed, as early as $28 \mathrm{~h}$ after infection (Fig. $4 I, J$ ).

The majority of virally labeled, GFP + SACs resided near cells with classically described ON-OFF-DSGC morphologies (Fig. 4I,J, 6): these RGCs had dendrites that stratified directly within the two ChAT laminae in the IPL and exhibited recursive looping of their dendritic arbors within the plane of each ChAT lamina (Vaney and Pow, 2000; Demb, 2007; Wei et al., 2011). The number of GFP + SACs with dendrites residing within the dendritic field of a GFP + RGC was quantified each day following infection. The overall number of RGCs trans- 


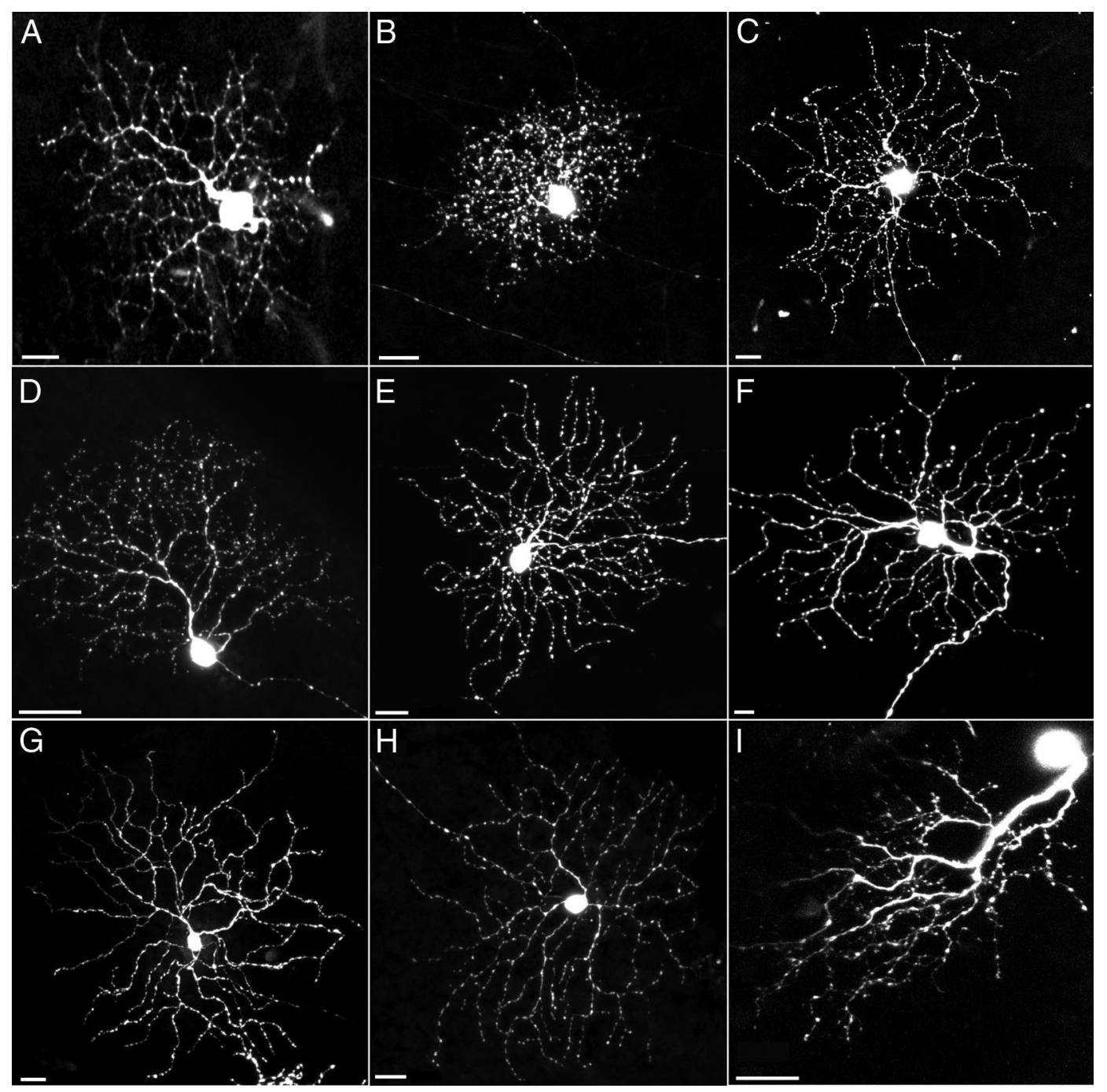

Figure 3. Most of the major classes of RGCs could be observed from LGN injection of rVSV(A/RG) pseudotyped with RABV G. Among the RGCs labeled, using the classification of murine RGCS reported previously (Völgyi et al., 2009), were small dendritic arbor RGCS (A, B), G7 RGCs (Völgyi et al., 2009), which are similar to outer $\delta$-cells in the rat retina (C), Cdh3-RGCs (0sterhout et al., 2011) (D), ON-OFF-DSGCS, which respond in a directionally specific manner and stratify in both the $0 \mathrm{~N}$ and $0 \mathrm{FF}$ ChAT laminae (E), ON-DS GCS, which respond in a directionally specific manner and stratify in only the ON ChAT lamina $(\boldsymbol{F}), 0 \mathrm{FF}-\alpha$, OFF-brisk transient RGCS $(\boldsymbol{G}), \mathrm{ON}-\alpha$, ON-brisk transient RGCS $(\boldsymbol{H})$, and OFF-DSGCS, which respond in a directionally specific manner and stratify above the OFF-ChAT lamina (I). Images were taken 2 dpi. Scale bars, $20 \mu \mathrm{m}$.

mitting to SACs increased until 5 dpi to $59 \%(N=80)$, and then tapered off slightly (Fig. 5C). Interestingly, the number of SACs labeled per RGC held constant over time (Fig. 5D). Only 2 of 411 virally labeled amacrine cells did not express the Cre-history reporter, tdTomato. However, both had dendrites in the OFF-ChAT lamina, and both colabeled with an antiChAT antibody (data not shown). Together, these data indicate that this viral strategy is useful for charting the types of RGCs that project to a given central target (in this case the LGN) and for labeling interneurons presynaptic to those RGCs (in this case, Cre-TVA-tdTomato-expressing SACs).

VSV replication is toxic to cells, as is replication of RABV and PRV. Following infection with any of these viruses, the goal is to examine the tissue before the death of cells infected early during the course of viral replication/transmission. While $60 \%$ of labeled RGCs contained a nearby virally labeled SAC, by $5 \mathrm{~d}$ after infection of the LGN with $\mathrm{rVSV}(\mathrm{A} / \mathrm{RG})$, many RGCs were too sick to permit unambiguous identification of their morphology. An analysis of the types of RGCs that were virally labeled, and that transmitted to SACs, was thus performed at 2 dpi, when RGCs still appeared healthy. Eighteen percent ( 2 of 11 ) of the ON- $\alpha$-RGCs, $32 \%$ ( 6 of 19) of the OFF- $\alpha$-RGCs, and $42 \%$ ( 8 of 19) of the OFF-DSGCs infected from the injection of the LGN transmitted virus to SACs by 2 dpi. By 2 dpi, infected ON-OFF-DSGCs transmitted to SACs in $48 \%$ (61 of 127 ) of cases (Fig. $5 B$ ). Since these four RGC subtypes together comprise $\sim 60 \%$ of all RGC types labeled (Fig. $5 A$ ), as calculated $2 \mathrm{dpi}$, and $59 \%$ of infected RGCs transmitted virus to SACs by $5 \mathrm{dpi}$, we can assume that nearly all infected RGCs that are synaptically connected to SACs transmitted virus to at least one SAC by $5 \mathrm{dpi}$. Other RGC types that transmitted virus to SACs (3 of 20) included two wide-field ON-RGCs, which stratified between the ChAT bands, and one medium-field OFF-RGC, which stratified between the OFF ChAT band and the inner nuclear layer.

In contrast to the transmission from DSGCs, RGCs with small dendritic arbors (Rockhill et al., 2002; Völgyi et al., 2009) that were infected from the LGN viral injection were never observed to transmit to SACs by 2 dpi ( 0 of 91 cells; Fig. $5 B$ ). Since $44 \%$ of the labeled RGCs were ON-OFF-DSGCs or ON-DSGCs (Fig. 

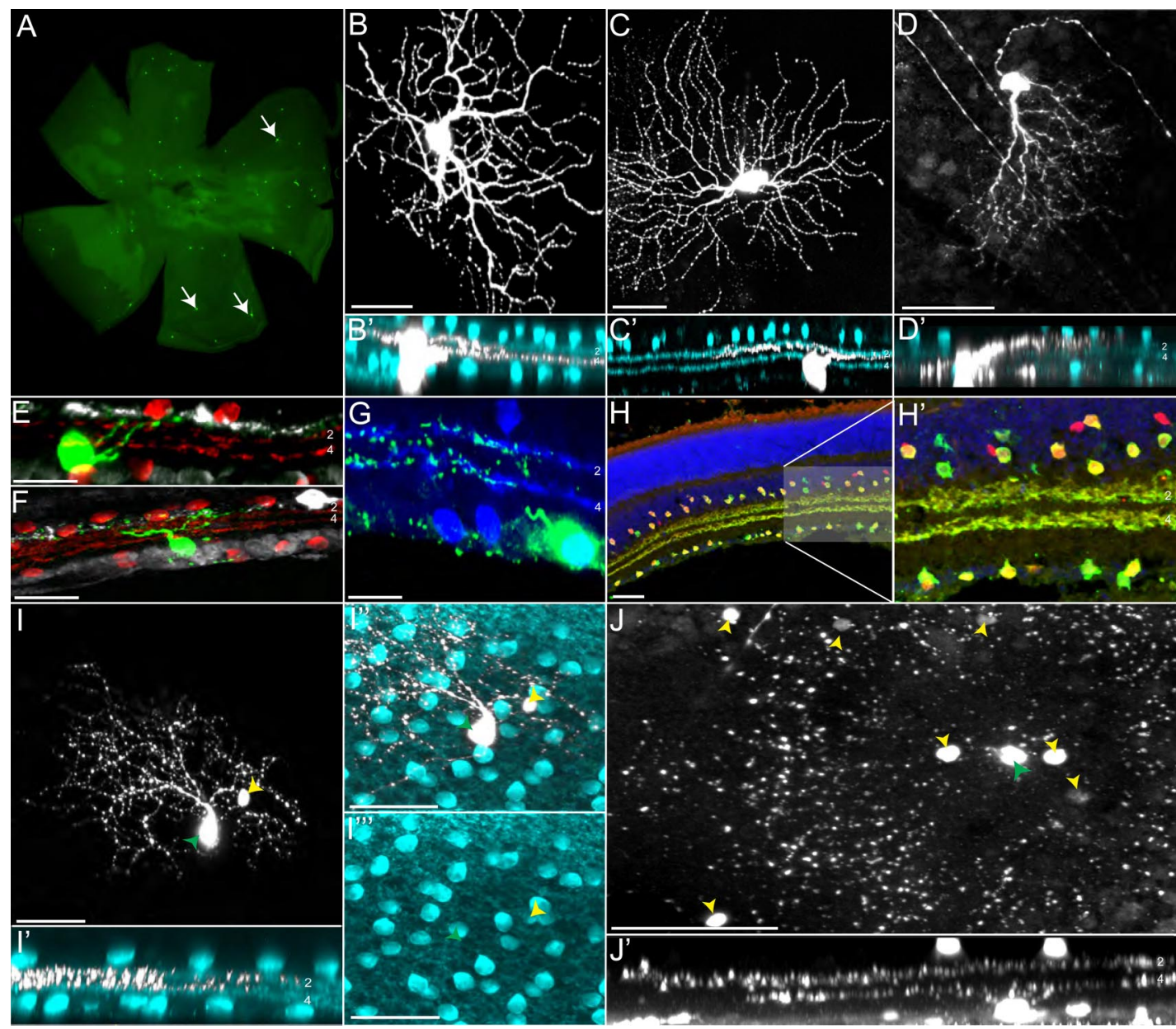

Figure 4. Injection of $r V S V(A / R G)$ pseudotyped with RABV G into the $L G N$ leads to infection of RGCs and transmission specifically to TVA-expressing $S A C s$. $A$, RGCS were labeled by a viral injection into the LGN (arrows indicate examples of RGCS). Injection labeled a wide variety of RGCs projecting into the LGN, including those that were morphologically consistent with ON-OFF-DSGCs (B), OFF- $\alpha(\boldsymbol{C})$, and asymmetric nasal-directed J-RGCS (D) (among others, Fig. 4). $\boldsymbol{B}^{\prime}, \boldsymbol{C}^{\prime}$, and $\boldsymbol{D}^{\prime}$ show side views of the cells in $\boldsymbol{B}-\boldsymbol{D}$, indicating the IPL lamination patterns of these RGCs. Chat laminae are indicated by the numbers 2 and 4 , based on labeling of laminae 2 and 4 with an anti-ChAT antibody, shown in cyan. $E$, $F$, Examples of infected OFF-DSGCS (green), which stratified between the TH (white, lamina 1) and ChAT (red, lamina 2) laminae. Images are z-stack reconstructions of confocal images. G, A cross section showing an example of an infected ON-OFF-DSGC, stratifying exclusively in ChAT laminae 2 and 4 (blue stripes). $\boldsymbol{H}, \boldsymbol{H}^{\prime}$, The expression pattern of recombined tdTomato that resulted from a cross of a conditional tdTomato allele to a ChAT-Cre mouse (red). Green shows ChAT antibody staining. While all ON-SACs were both red and green, some OFF-SACs were red (Cre-expression history), but not green (ChAT antibody), or green and not red. $I$, A pair of GFP-labeled cells are shown (white), an asymmetric ON-OFF-DSGC (green arrowhead) and an OFF-SAC (yellow arrowhead). $I$ and $I^{\prime}$ highlight the RGC dendritic processes, while $I^{\prime \prime}$ and $\boldsymbol{I}^{\prime \prime \prime}$ indicate that the putative SAC indeed stains with an anti-ChAT antibody (cyan). J, An ON-OFF-DSGC (green arrowhead) transmitted rVSV(A/RG) to both ON and OFF-SACS (yellow arrowheads). J', Note how this DSGC was bistratified in the ON and OFF ChAT laminae and that the SAC somas were predominately located within $\sim 180^{\circ}$ of the dendritic field of the RGC. The image shown in $J$ corresponds to Fig. $6 F$. All images of viral infection were taken 2 dpi. Scale bars: $\boldsymbol{E}, \boldsymbol{F}, 15 \mu \mathrm{m}$; rest, $50 \mu \mathrm{m}$. Images: $\boldsymbol{A}-\boldsymbol{F}, \boldsymbol{I}, 2 \mathrm{dpi} ; \boldsymbol{G}, \boldsymbol{J}, 4 \mathrm{dpi}$.

$5 A$ ), the majority ( 44 of 59; 75\%) of RGC-to-SAC connectivity we observed occurred via synapses between SACs and ON-OFFDSGC and ON-DSGCs. These results are as expected, as SACs provide robust input to ON-OFF and ON-DSGCs and, as described above, provide a mechanism for a direction-selective response to visual stimuli.

\section{Viral labeling reveals local patterns of}

\section{SAC-to-DSGC connectivity}

Models of retinal direction selectivity indicate that ON-OFFDSGCs receive the majority of their inhibitory synapses from SACs whose cell bodies lie on the null side of the DSGC soma (Demb, 2007; Lee et al., 2010; Briggman et al., 2011; Wei et al., 2011). Thus, if rVSV was faithfully transmitted via synaptic connections retrogradely from a single ON-OFF-DSGC to multiple SACs, the infected SACs should be located primarily off to one side of the ON-OFF-DSGC with whom they are connected. Indeed, we observed an apparent asymmetry in the spatial distribu- tion of GFP + SACs relative to the GFP + ON-OFF-DSGCs: the SACs were distributed primarily to one side (defined as $180^{\circ}$ of the dendritic field) of the ON-OFF-DSGC soma (Fig. 6A-F). The apparent asymmetry depended on the angle chosen to separate the SACs into two groups. We chose, by eye, an angle of optimal separation, such that SACs on one side were maximized (max side) and SACs on the other side were minimized (min side; Fig. $6 A)$. We analyzed 15 DSGCs with three to eight labeled SACs each (Fig. 6A-F). Across DSGCs, there were 84 SACs in total, and 75 of these were on the max side of the DSGC arbors (Fig. 6I).

To determine whether the apparent asymmetry in SAC location was statistically significant, we performed a bootstrapping analysis (Efron and Tibshirani, 1993). We simulated data, given the null hypothesis of no asymmetry, by randomizing the angle of SACs for each of the 15 DSGCs (three to eight SACs each, identical with the original data; binned into 16 radial sectors in each case). An algorithm determined the angle of optimal separation for each model DSGC (Fig. 6G), and we summed the total num- 
A

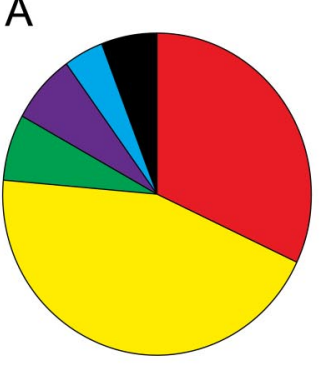

C

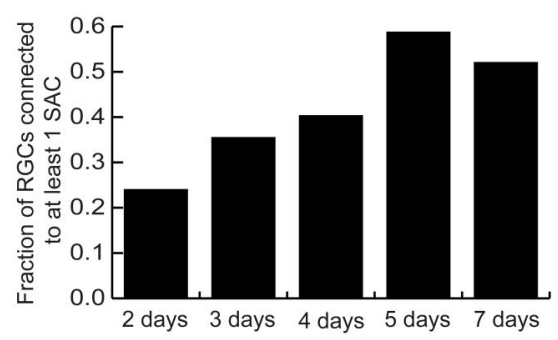

B

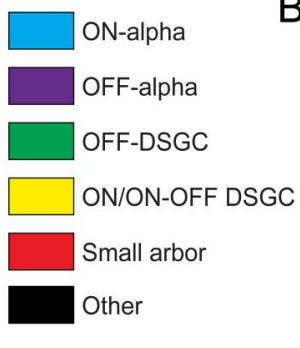

$D$

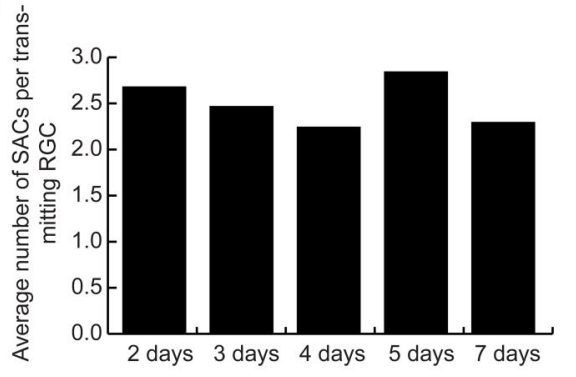

E F

Summary of labeled RGCs and SACs
\begin{tabular}{|c|c|}
\hline \# Retinae & 42 \\
\hline \# RGCs/retina & $1-52$ \\
\hline $\begin{array}{c}\text { \# RGCs @ 2dpi } \\
\text { analyzed (A-B) }\end{array}$ & 288 \\
\hline $\begin{array}{c}\text { \# RGCs @ 2-7dpi } \\
\text { analyzed (C-D) }\end{array}$ & 348 \\
\hline $\begin{array}{c}\text { \# RGCs transmitting virus } \\
\text { to TVA-negative cells }\end{array}$ & $0 / 228$ \\
\hline $\begin{array}{c}\text { \# tdTomato-negative } \\
\text { amacrines infected }\end{array}$ & $2 / 411$ \\
\hline
\end{tabular}

\begin{tabular}{|c|c|c|}
\hline RGC Type & $\begin{array}{c}\text { Fraction transmitting to } \\
\text { SACs at 2 dpi }\end{array}$ & Distribution of SACs around RGC \\
\hline ON-OFF and ON-DS & $61 / 127(48 \%)$ & asymmetric for ON-OFF, unknown for ON \\
\hline OFF-DS & $8 / 19(42 \%)$ & asymmetric \\
\hline OFF-alpha & $6 / 19(32 \%)$ & unknown \\
\hline ON-alpha & $2 / 11(18 \%)$ & unknown \\
\hline Small arbor & $0 / 91(0 \%)$ & - \\
\hline Other & $3 / 20(15 \%)$ & - \\
\hline
\end{tabular}

Figure 5. Quantification of SAC labeling from LGN injection of rVSV(A/RG) pseudotyped with RABV G. $A$, The percentages of RGC types labeled from initial $L G N$ infection ( $N=288$ RGCS) at 2 dpi, assessed by morphology (for examples, see Figs. 3 and 4). Sixty-nine of those RGCs contributed to the $N=348$ assessed for spread from 2 to 7 dpi (C, $\boldsymbol{D}$ ). $\boldsymbol{B}, 0 \mathrm{~N}-0 \mathrm{FF}$ and $0 \mathrm{~N}-\mathrm{DSGCS}$ were the most efficient at labeling SACs (61 of 127), and while the efficiency of OFF-DSGCs ( 8 of 19) and OFF ( 6 of 19) and ON- $\alpha$ ( 2 of 11) RGCs was less, they were more efficient than small-arbor RGCs (0\%). 0 ther RGCS that transmitted virus to SACs included two wide-field transient ON-RGCs that stratified between the ChAT bands and transmitted to ON-SACs, and one wide-field OFF-RGC, morphologically similar to a W7 RGC (Kim et al., 2010), a sustained OFF-RGC that stratified above and below the OFF-ChAT band, that transmitted virus to an ON-SAC. All counts from morphologically identified RGCs were obtained 2 dpi. $C, D$, The number of RGCS ( $N=348)$ that transmitted virus to SACs increased over time, up to $59 \%$ at 5 dpi $(\boldsymbol{C})$, while the number of SACs labeled per RGC remained constant (D). $\boldsymbol{E}$, Summary of numbers of RGCs and SACs analyzed in this paper. $\boldsymbol{F}$, Breakdown of transmission efficiency to SACs per RGC subtype, and SAC distributions around RGC types, if applicable.

ber of SACs on the max side. In an example simulation, there were a total of 68 SACs on the max side (Fig. $6 \mathrm{H}$ ). We repeated the simulation 1,000,000 times and generated a distribution of total SACs on the max side in each group of 15 model DSGCs. The probability of obtaining or exceeding the value in the real data (75) by chance was $p<0.01$.

We also searched for evidence of SAC-to-SAC transmission (i.e., virally labeled SACs whose processes did not overlap with those of a labeled RGC). However, no evidence of SAC-to-SAC spread was seen. The relative position of the labeled SACs and ON-OFF-DSGCs supports the prediction that $\operatorname{rVSV}(\mathrm{A} / \mathrm{RG})$ spreads transsynaptically in the retrograde direction and in a TVA-specific manner. The asymmetry in the location of the somas of the SACs, and the distribution of their dendrites within an ON-OFF-DSGC arbor, reinforces the classically held model of SAC-to-DSGC connectivity (Demb, 2007). The side with labeled SACs identifies the putative null side of the ON-OFF-DSGC and thereby also predicts the directional tuning of the DSGC.

Noncanonical DSGC connectivity revealed by selective RGCto-SAC retrograde transsynaptic tracing

In addition to the predicted spatial patterns of SAC labeling described above, there were interesting and unexpected features.
For example, while ON-DSGCs transmitted primarily to ONSACs, we occasionally observed that ON-DSGCs transmitted the virus to SACs whose dendritic arbors stratified in the OFF layer (Fig. 7A). While the ON-DSGC did not stratify in the OFF-ChAT band, some ON-DSGCs are known to extend vertical processes to the OFF-ChAT lamina and under certain conditions respond to light offset (Fig. 7A', inset) (Sun et al., 2006). The vertical processes were seen here as well in the two cases in which an ON-DSGC transmitted to an OFF-SAC (Fig. 7 $A^{\prime}$ ). The observation of viral transmission between ON-DSGCs and OFF-SACs supports the previous observations of OFF responses (Sun et al., 2006) and suggests that the response is via direct connections with presynaptic cells in the OFF layer. This observation also argues that the viral strategy we describe here is capable of detecting small cohorts of interneurons that synapse onto RGCs and thus is not biased to reveal only large pools of similar inputs.

\section{Unexpected synaptic coupling between SACs and other RGC types}

Interestingly, labeled SAC dendrites were often located within the dendritic territory of RGCs whose morphology was clearly not that of ON-DS or ON-OFF-DSGCs (Figs. 5A, B,F, 7B-G). For example, OFF- $\alpha$-RGCs transmitted virus to OFF-SACs; and ON- 

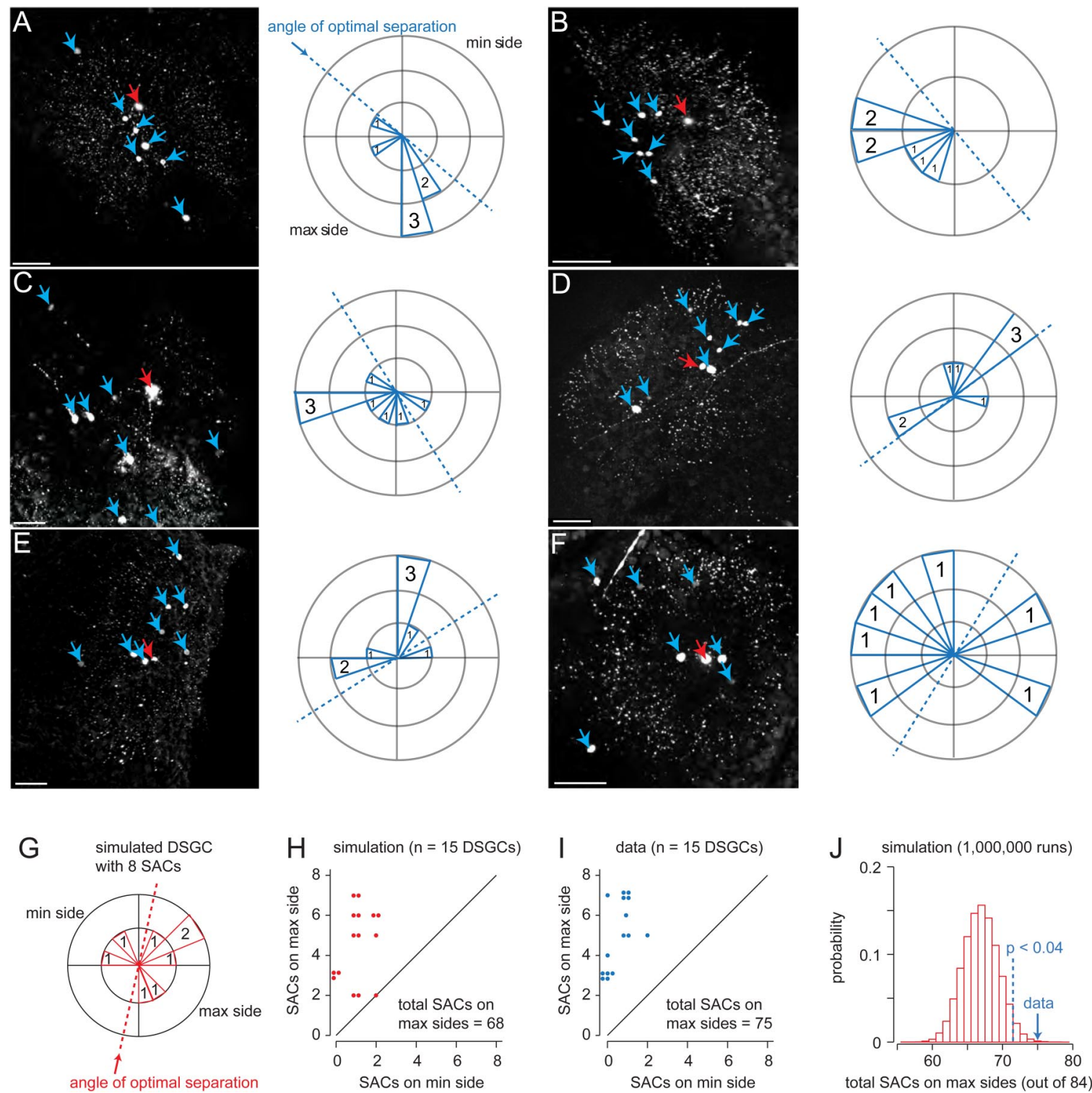

total SACs on max sides (out of 84)

Figure 6. Labeled SACS (blue arrows) from ON-OFF-DSGCS (red arrow) are preferentially located in one-half of the DSGC receptive field. $A-F$, Polar plots indicate the angle from the $0 N-0 F F-D S G C$ soma to the SAC soma, and number of SACs at those locations. In each case, an angle of optimal separation (dashed blue line) was chosen that maximized the number of $S A C s$ on one side (180 ; max side) and minimized the number of $S A C s$ on the other side (min side). In some cases, the angle of optimal separation was not unique (e.g., two angles could yield the same maximal $5: 2$ ratio in $\boldsymbol{F}$ ). All images were taken $4 \mathrm{dpi}$. Scale bars, $50 \mu \mathrm{m} . \mathbf{G}$, For each DSGC $(n=15)$, the labeled SACs were reassigned random angles in a simulation, given the null hypothesis (no asymmetry in SAC location), and an angle of optimal separation was determined as with the real data. $\boldsymbol{H}$, A simulation of 15 DSGCS shows the number of SACS on the max versus min sides for each model DSGC (red points; overlapping points have been displaced slightly for visualization). $\boldsymbol{I}$, Same format as $\boldsymbol{H}$ for the 15 DSGCs in the real dataset. $J$, Running the simulation $1,000,000$ times yielded a distribution of total SACs on the max sides (of 84 SACs total) for each group of 15 simulated DSGCS. The probability of obtaining the actual value (75 SACs on the max sides) by chance was $p<0.01$.

$\alpha$-RGCs transmitted virus to ON-SACs (Fig. $7 B, C$ ). It was previously reported that both $\mathrm{ON}$ - and OFF- $\alpha$-cells stratify primarily on the vitreal side of the ON- or OFF-ChAT bands (Huberman et al., 2008; Manookin et al., 2008; van Wyk et al., 2009). However, we found that both $\alpha$-cell types costratified with SACs over short distances, as reported in cat ( $\alpha$-cells) (Vardi et al., 1989) and primate (parasol cells) (Jacoby et al., 1996), enabling direct synaptic connections. $\alpha$-RGCs fire action potentials in response to acetylcholine administration and are suppressed by cholinergic antagonists; these previous findings suggest direct synaptic connections between SACs and $\alpha$-RGCs (Straschill and Perwein, 1973; Ikeda and Sheardown, 1982; Wässle et al., 1986; Schmidt et al., 1987; Vardi et al., 1989; Zhang et al., 2005). The viral labeling pattern provides strong evidence of direct connections between these cell types.
Another example of novel SAC-to-RGC connectivity revealed by VSV tracing is shown in Figure $7 D-G$. RGCs that stratified between the OFF-ChAT lamina and the tyrosine hydroxylase amacrine (TH amacrine) lamina (Fig. 4E,F) exhibited either asymmetrical (Fig. $7 D, E$ ) or symmetrical (Fig. $7 F, G$ ) dendritic arbors. These features resemble the OFF-DSGCs described as "J-RGCs" (Kim et al., 2008). Asymmetric J-RGCs were previously shown to be DS, but since they do not costratify with SACs, they were not believed to receive direct input from SACs nor acquire their DS tuning from SACs. By contrast, transmission of rVSV revealed synaptic connections between J-RGCs and OFF SACs, and in a minority of cases, between J-RGCs and ON SACs. The connection with ON SACs may explain excitatory responses, under certain conditions, to light increments in these OFF cells (Kim et al., 2008). Interestingly, in each of the five observed 

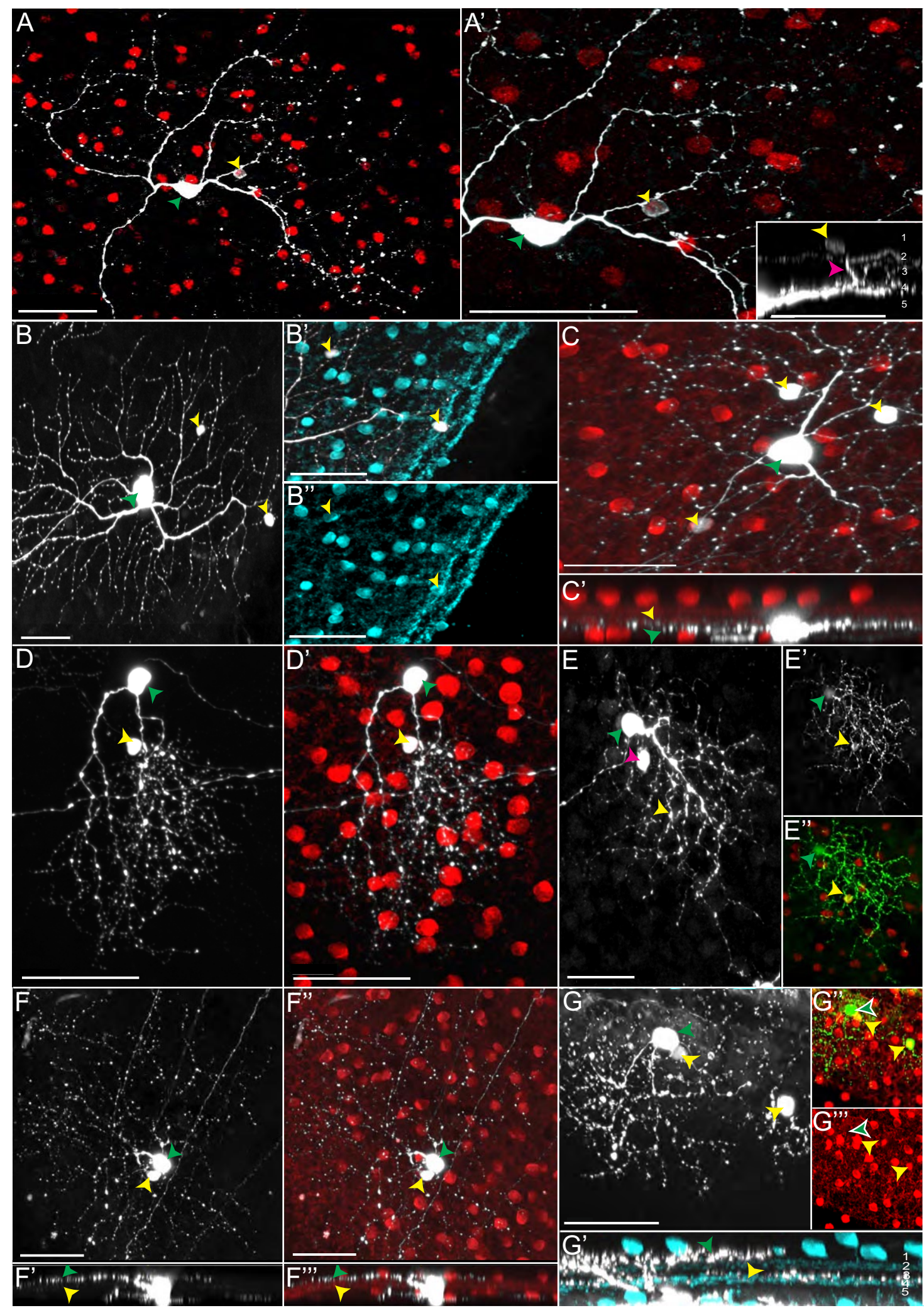

Figure 7. $\operatorname{rVSV}\left(\mathrm{A} / \mathrm{RG}\right.$ ) provides evidence for novel direct synaptic connectivity of SACS. $A, A^{\prime}$, An ON-DSGC (green arrowhead), which sent vertical processes to the $0 \mathrm{FF}-\mathrm{ChAT}$ lamina, transmitted virus to an OFF-SAC (yellow arrowhead). These cells did not costratify, as the ON-DSGC stratified exclusively in lamina 4, and the OFF-SAC stratified in lamina 2. $\boldsymbol{A}^{\prime}$, A higher magnification of $\boldsymbol{A}$, and the inset shows the vertical processes from the ON-DSGC (magenta arrow), while the yellow arrowhead indicates the SAC. White, Viral fluorescence; red, $C$ re reporter. $B, C, O F F-\alpha$ - and ON- $\alpha$-RGCS showed connectivity to OFF-SACs or ON-SACS, respectively. $\boldsymbol{B}$ shows the morphology of an OFF- $\alpha$-RGC (green arrowhead) and OFF-SACs (yellow arrowheads), and $\boldsymbol{B}^{\prime}$ and $\boldsymbol{B}^{\prime \prime}$ show a higher magnification of the two non-RGCs, indicating that the cells (white) were indeed SACs, as evidenced by overlap with an anti-ChAT antibody (cyan). Only OFF-SACs were labeled from this RGC type. $C-C^{\prime \prime}$, An example of an $0 \mathrm{~N}-\alpha-R G C$ (green arrowhead) labeling ON-SACs (yellow arrowheads). $C^{\prime}$ is a cross section through the image shown in $C$ to indicate dendritic lamination location. White, Viral fluorescence; red, Cre reporter. $\mathbf{D}-\mathbf{G}$, Viral transmission to SACs occurred from asymmetric and symmetric OFF-DSGCS. D, $\mathbf{D}^{\prime}$, A maximum-intensity projection, indicating an asymmetric OFF-DSGC (green arrowhead) and an OFF-SAC (yellow arrowhead). White, Viral fluorescence; red, Cre-mediated tdTomato expression. (Figure legend continues.) 

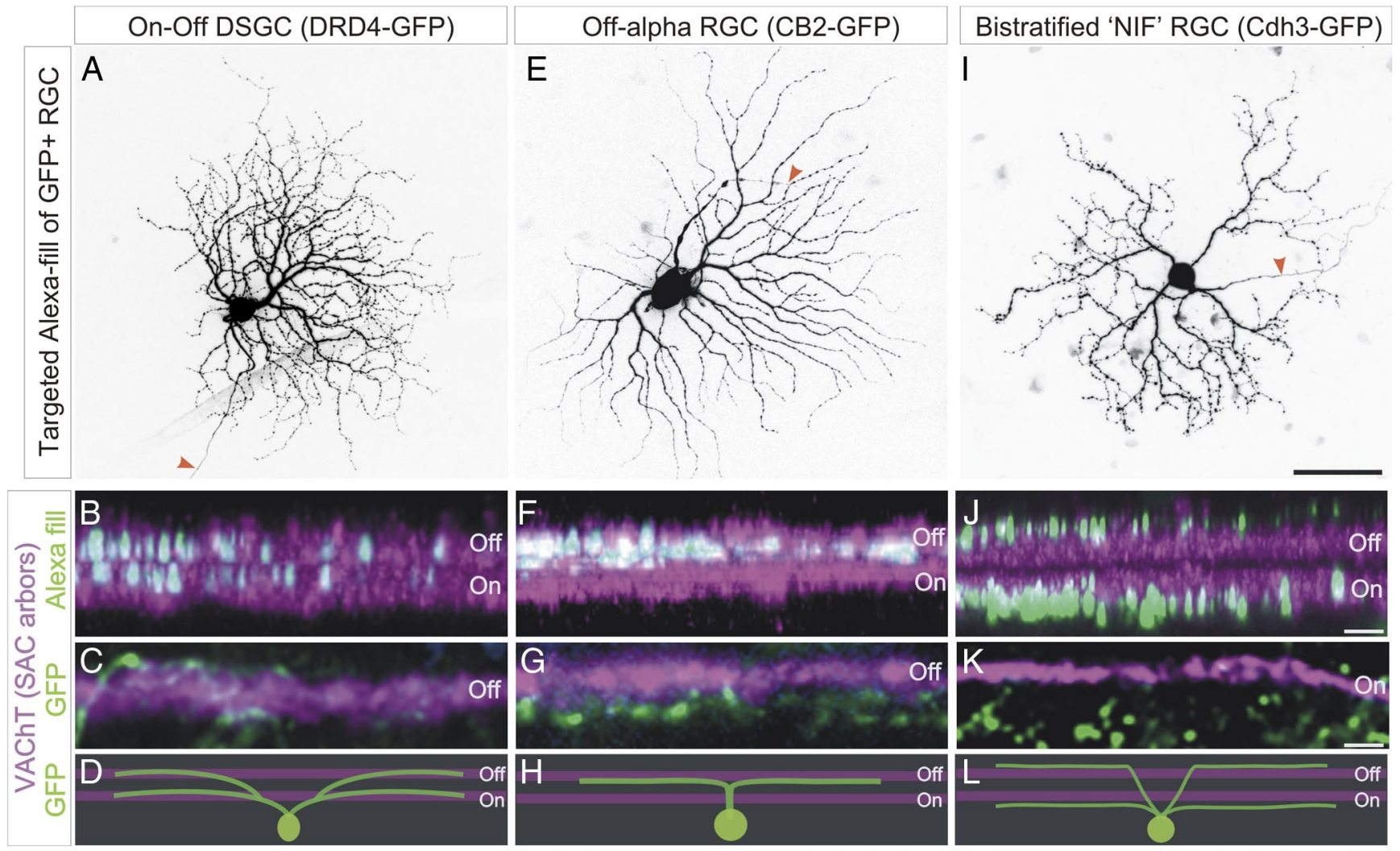

Figure 8. Dendritic stratification of genetically identified RGC subtypes relative to SAC-cholinergic lamina in the IPL. $A, E, I$, Alexa 555 fills of individual GFP + RGCS (targeted on the basis of GFP fluorescence). The location of the dendritic arbors (shown in green) from ON-0FF-DSGCS $(\boldsymbol{B}, \boldsymbol{C}), 0 \mathrm{FF}-\alpha-\operatorname{RGCS}(\boldsymbol{F}, \boldsymbol{G})$, and bistratified NIF RGCS $(\boldsymbol{J}, \boldsymbol{K})$ relative to labeled SAC processes (magenta) are shown, with overlap appearing as light blue/white. $\boldsymbol{D}, \boldsymbol{H}, \mathbf{L}$, Summary schematics of the RGC dendritic arborization patterns relative to the VAChT labeling (SAC arbors) for each RGC subtype. Scale bar: $A, E, I, 50 \mu \mathrm{m} ; \boldsymbol{B}, \boldsymbol{F}, \boldsymbol{J}, 15 \mu \mathrm{m} ; \boldsymbol{C}, \boldsymbol{G}, \boldsymbol{K}, 10 \mu \mathrm{m}$.

asymmetrical J-RGCs that transmitted virus to SACs, all of the labeled SACs were located on the null side of the DSGC soma, similar to the case of ON-OFF-DSGCs.

\section{Morphology and stratification of genetically identified RGC subtypes relative to SACs}

Our viral tracing results indicated that DSGCs, as well as several other types of non-DSGCs ( $\alpha$-RGCs in particular) receive direct synaptic input from SACs. We therefore examined the proximity of SAC arbors to the dendritic processes of various genetically

\section{$\leftarrow$}

(Figure legend continued.) E, A maximum-intensity projection of an OFF-DSGC (green arrowhead), with two labeled SACs (yellow and magenta arrowheads). While the ON-SAC in $\boldsymbol{E}$ is easily observed (magenta arrowhead), the OFF-SAC in $\boldsymbol{E}^{\prime}$ (yellow arrowhead) is obscured by the OFF-DSGC dendrites in the maximum-intensity projections. $E^{\prime \prime}$, This cell also stains positive for the anti-ChAT antibody. Green, viral fluorescence; red, Cre-mediated tdTomato expression. $\boldsymbol{F}-\boldsymbol{F}^{\prime \prime \prime}$, A symmetric $0 \mathrm{FF}-\mathrm{DSGC}$ (green arrowhead) transmitted virus to an ON-SAC (yellow arrowhead). The stratification of the OFF-DSGC $\left(\boldsymbol{F}^{\prime}, \boldsymbol{F}^{\prime \prime \prime}\right)$ is above the OFF-ChAT lamina 2, while that of the SAC is in the ON-ChAT lamina. White, Viral fluorescence; red, Cre-mediated tdTomato expression. G-G'", A symmetric OFF-DSGC (green arrowhead) and two nearby ON-SACs (yellow arrowheads). $G$ shows a Z-section through lamina $4 . \mathbf{G}^{\prime}$ is an optical section of the same cells, which indicates that the stratification of the OFF-DSGC was above lamina 2 (green arrowhead), and the ON-SAC stratification was in lamina 4 (yellow arrowhead). The processes of these neurons overlapped, even though they did not costratify. White, viral fluorescence; cyan, anti-ChAT antibody. G" and $G^{\prime \prime \prime}$ indicate that the RGC (white arrowhead with green fill) did not express ChAT, while the SACs (yellow arrowheads) did express ChAT, as indicated by colabel of viral GFP and tdTomato (insets). Images: $\boldsymbol{B}-\boldsymbol{E}$, taken $2 \mathrm{dpi} ; \boldsymbol{F}$, taken $3 \mathrm{dpi} ; \boldsymbol{A}, \boldsymbol{G}$, taken $4 \mathrm{dpi}$. Scale bars, $50 \mu \mathrm{m}$. identified RGC subtypes using transgenic mice in which GFP is selectively expressed in anatomically and physiologically verified ON-OFF-DSGCs (DRD4-GFP mice) (Huberman et al., 2009; Kay et al., 2011; Wei et al., 2011), transient OFF- $\alpha$-RGCs (CB2GFP mice) (Huberman et al., 2008; Völgyi et al., 2009, and a subtype of non-image-forming ("NIF") RGCs (Cdh3-GFP mice) (Osterhout et al., 2011) (D. Berson, unpublished data). The GFP+ somas of each RGC subtype were targeted with an intracellular glass electrode in freshly dissected, live retinal explants (see Materials and Methods), and then filled with Alexa 555 fluorescent dye. After the cell was completely filled, the retina was fixed and stained for GFP, VAChT, and DAPI, and imaged. When viewed en face, the characteristic morphologies of ON-OFFDSGCs: looping arborizations and dense arbors studded with postsynaptic swellings were observed $(N=10$ cells $)$ in all DRD4GFP RGCs (Fig. 8A). $\alpha$-RGCs targeted in CB2-GFP mice, by contrast, all had relatively large-caliber, smooth dendrites that lacked looping arborizations (Fig. $8 E)(N=10$ cells). The bistratified GFP RGCs in the Cdh3-GFP mouse all had relatively sparse and "spiny" dendrites (Fig. $8 I)(N=10$ cells). Every targeted, filled GFP + cell was verified as an RGC by the presence of an axon (Fig. 8A,E,I, orange arrowheads).

By comparing the dendrites of the filled cells with VAChT immunostaining (which labels SAC arbors), we confirmed that the genetically identified ON-OFF-DSGCs stratify their dendrites directly within the OFF- and ON-ChAT laminae (Fig. 8 B). Higher magnification views of the individual lamina showed GFP+ dendrites comingled along the top and throughout the plexus of each individual SAC lamina (Fig. 8C; summarized in $D$ ). 

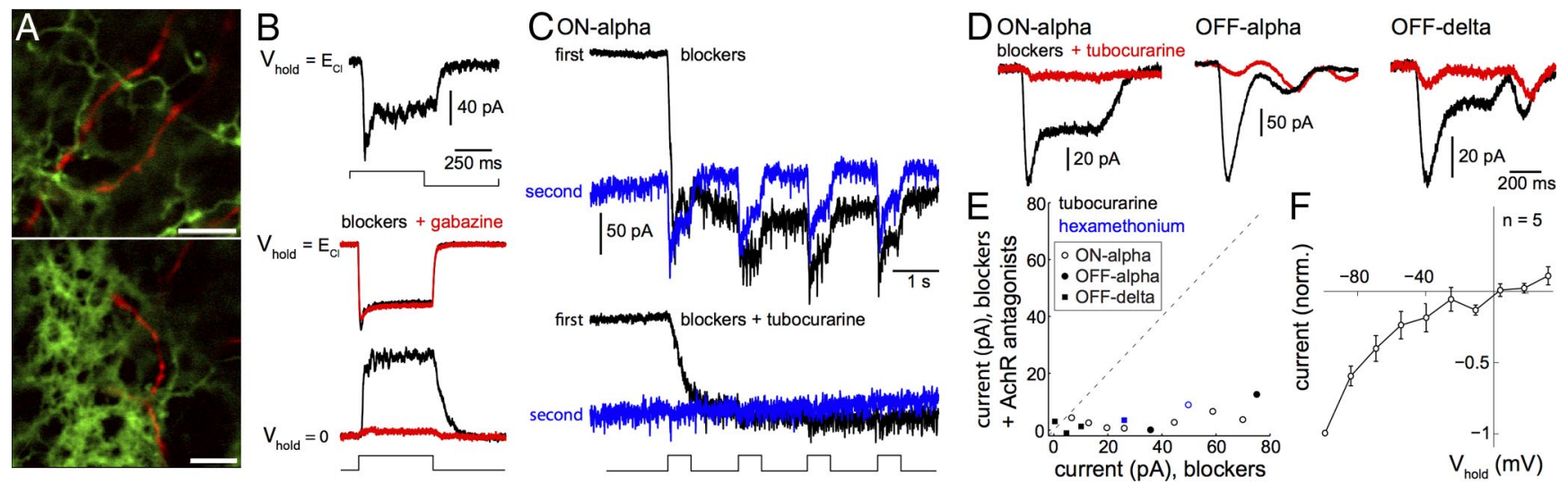

Figure 9. Functional cholinergic connections between SACs and identified RGC types. $\boldsymbol{A}$, Two-photon fluorescence images of SAC dendrites (green) and ON- $\alpha$-RGC dendrites (red). $\boldsymbol{B}$, Whole-cell patch recording of a ChR2-expressing SAC from a ChAT-Cre/ChR2 retina. The top trace shows the response to a $100 \%$ contrast modulation of a spot (400 $\mu \mathrm{m}$ diameter) on a photopic background $\left(\sim 10^{4} R^{*} \cdot\right.$ cone $\left.^{-1} \cdot \mathrm{s}^{-1}\right)$. The middle and bottom traces show the response to ChR2 activation in the presence of synaptic blockers (DNQX, D-AP5, L-AP4, strychnine), before and after adding gabazine. $C$, Whole-cell patch recording from an $0 \mathrm{~N}-\alpha$-RGC in a ChAT-Cre/ChR2 retina in the presence of synaptic blockers (DNQX, D-AP5, L-AP4, strychnine, gabazine). Four pulses of a ChR2activating stimulus evoked fast tubocurarine-sensitive excitatory currents and a slow, intrinsic melanopsin-mediated inward current. The melanopsin response evoked on the first trial recovered with a time constant $>30$ s and persisted throughout the second trial (intertrial interval, $2.5 \mathrm{~s}$ ). $\boldsymbol{D}$, Tubocurarine-sensitive excitatory currents evoked by ChR2 activation, recorded in the presence of synaptic blockers (DNQX, D-AP5, L-AP4, strychnine, gabazine). Responses (average of $>10$ ChR2 activations) were observed in 0N- $\alpha$ cells ( 9 of 9 ), 0 FF- $\alpha$-RGCs (4 of 4 ), and 0FF- $\delta$-RGCs (7 of 8). $\boldsymbol{E}$, Pharmacological block with AChR antagonists tubocurarine (50 $\mu \mathrm{M})$ and hexamethonium (100 $\mu \mathrm{m})$ strongly suppressed the excitatory input evoked by ChR2 activation in the presence of synaptic blockers. $F$, Current-voltage relationship of the RGC response evoked by ChR2 activation in the ChAT-Cre/ChR2 retina (average of $40 \mathrm{~N}$ - $\alpha$ and $10 \mathrm{FF}-\delta$ cell). AChR-mediated responses were recorded in the presence of synaptic blockers (described in $\boldsymbol{D}$ ) and normalized to the response at the most negative holding potential. Error bars indicate $S E M$ across cells. Scale bar, $10 \mu \mathrm{m}$.

The genetically labeled and dye-filled OFF- $\alpha$-RGCs stratified their dendrites along the vitreal side of the OFF-SAC lamina; the GFP dendrites were rarely observed within the OFF-SAC lamina itself (Fig. $8 F, G$; summarized in $H$ ). The non-image-forming RGCs that express GFP in Cdh3-GFP mice showed a pattern distinct from both ON-OFF-DSGCs or $\alpha$-RGCs by projecting their dendrites scleral to the OFF-SAC lamina, and vitreal to the ON-SAC lamina (Fig. $8 \mathrm{~J}$, $K$; summarized in $L$ ).

\section{Evidence for functional connections between SACs and non-DSGCs}

To further test the existence of novel connections between SACs and RGCs revealed by viral tracing, we examined functional connections between SACs and $\alpha$-type RGCs using optogenetics and whole-cell recording. Recordings were made in retinas where SACs expressed ChR2 (Fig. 9A). This allowed selective activation of SACs in the presence of synaptic blockers that suppress photoreceptor-mediated light responses (see Materials and Methods). We first made whole-cell recordings from SACs under control conditions to measure the amplitude of light-evoked excitation (Fig. 9B). Excitatory currents evoked by high contrast modulation of a spot ( $400 \mu \mathrm{m}$ diameter) were $73 \pm 25$ pA (averaged over $0.5 \mathrm{~s}$; mean $\pm \mathrm{SD} ; N=11$ ).

SACs were recorded in the presence of synaptic blockers to verify that ChR2 was functional and that activation of ChR2 evoked synaptic release. ChR2 activation caused robust, sustained excitatory currents $(100 \pm 23 \mathrm{pA} ; N=5$; Fig. 9B). The amplitude of these ChR2-mediated currents was similar to those evoked by contrast, under control conditions (Fig. 9B). SACs make reciprocal GABAergic synapses with each other (Lee and Zhou, 2006). ChR2 activation (with ACh receptors blocked) caused inhibitory currents in a recorded cell consistent with ChR2 activation in neighboring SACs and subsequent GABA release onto the recorded cell. Indeed, the inhibitory current was blocked by the $\mathrm{GABA}_{\mathrm{A}}$ antagonist gabazine $(N=2$; Fig. $9 B)$. Thus, ChR2 activation of SACs evoked synaptic GABA release.

We next tested for functional synaptic connectivity between SACs and RGCs. We targeted RGCs with large somas, which could be divided into three types: ON- $\alpha$, OFF- $\alpha$ (or OFF-T), and OFF- $\delta$ (or OFF-S) (Murphy and Rieke, 2006; Margolis and Detwiler, 2007). OFF- $\alpha$ and OFF- $\delta$ cells were distinguished by their stratification: OFF- $\alpha$ cells stratify primarily on the vitreal side of the OFF ChAT band, whereas OFF- $\delta$ cells stratify on both sides of the OFF ChAT band, including processes near the inner nuclear layer (Margolis and Detwiler, 2007; Manookin et al., 2008; van Wyk et al., 2009; Kim et al., 2010). Dye fills of all three cell types showed areas where RGC dendrites costratified with SAC dendrites, permitting synaptic connectivity (illustrated for ON- $\alpha$ RGC dendrites in Fig. 9A).

In all three RGC types, activating ChR2 with 500 ms light pulses in the presence of synaptic blockers evoked robust excitatory currents in RGCs time-locked to the activation of SACs (Fig. 9C,D). In $\mathrm{ON}-\alpha$ cells, the first trial of ChR2-activating pulses always evoked an additional slow inward current that could be attributed to melanopsin-mediated intrinsic photosensitivity (Estevez et al., 2012). The recovery of the melanopsin-mediated response is slow (>30 s) and persisted throughout subsequent trials (Fig. 9C). In all cell types, the ACh receptor (AChR) antagonists, tubocurarine and hexamethonium, strongly suppressed the fast response to ChR2 activation (Fig. 9C-E); whereas the melanopsin-mediated response in ON- $\alpha$-RGCs persisted in the presence of AChR blockers (Fig. 9C). The current-voltage relationship of the ChR2-mediated response showed inward rectification (Fig. 9F), similar to that shown in previous recordings of AChR-mediated responses in cat and goldfish RGCs (Mathie et al., 1990; Yazejian and Fain, 1993; Cohen et al., 1994). ChR2 activation did not evoke consistent GABAergic inhibitory currents, tested in ON- $\alpha$-RGCs $(N=3$ ) (data not shown). Collectively, the combination of optogenetics and whole-cell recordings demonstrate functional cholinergic connections between SACs and three types of non-DSGCs: ON- $\alpha$, OFF- $\alpha$, and OFF- $\delta$.

\section{Discussion}

Viral transsynaptic tracing provides a novel complement to other methods for mapping CNS connectivity

Using a replication-competent rVSV engineered to encode a chimeric glycoprotein for retrograde tracing, we were able to define 


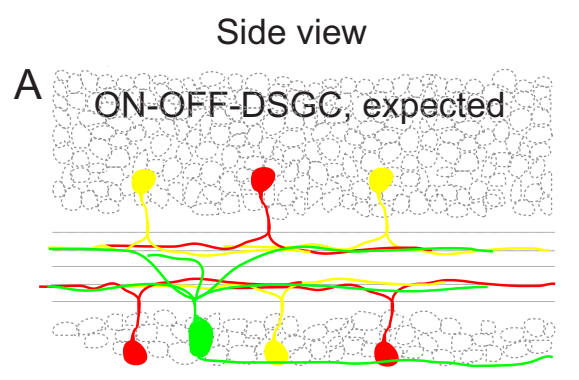

B

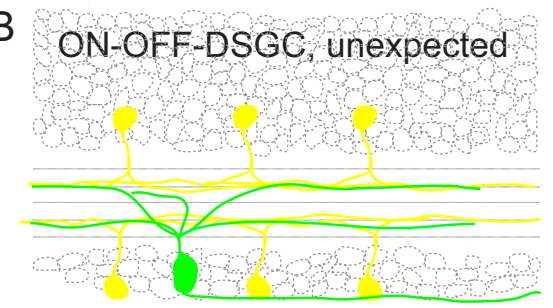

C

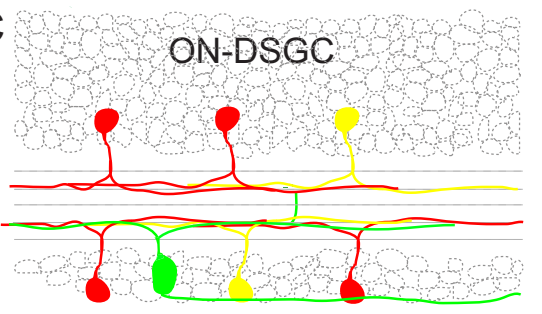

D

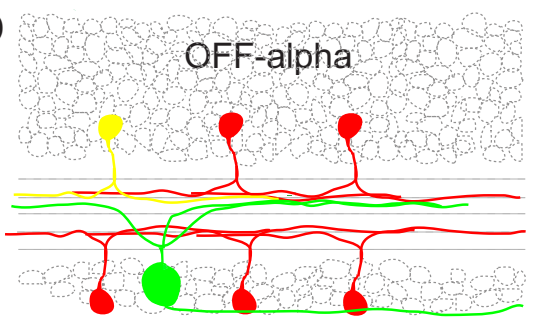

E

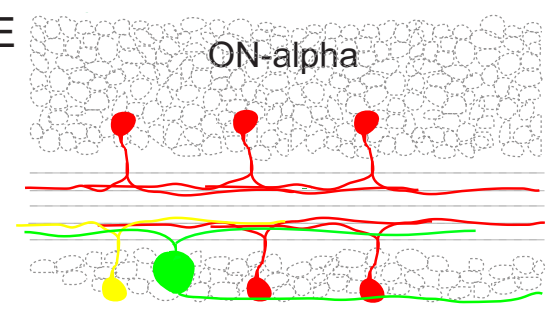

F

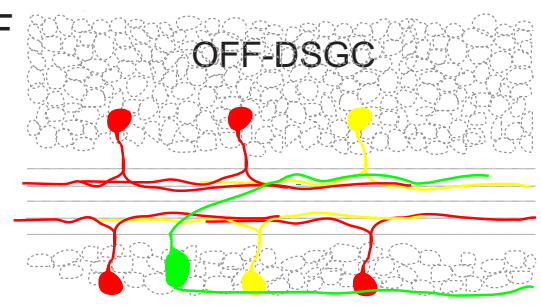

Top view
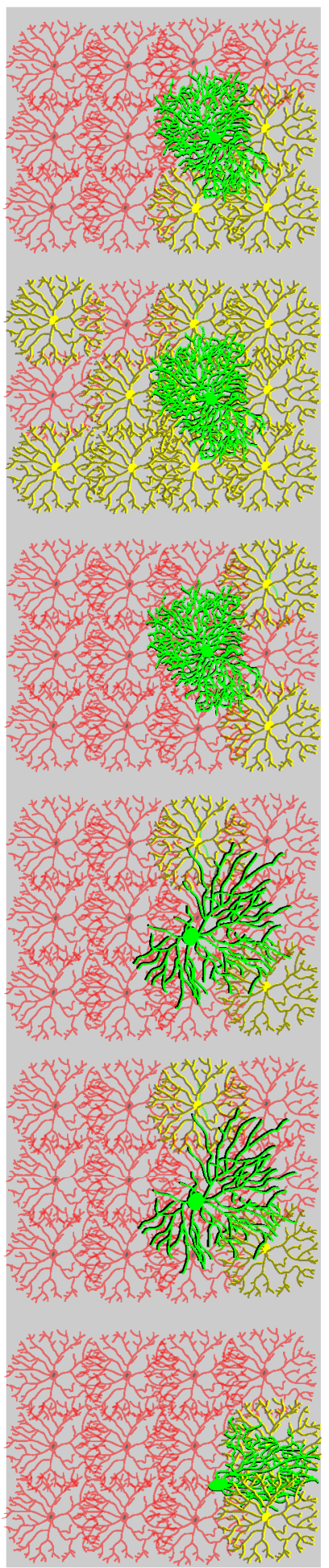

Observed?

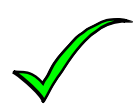

X
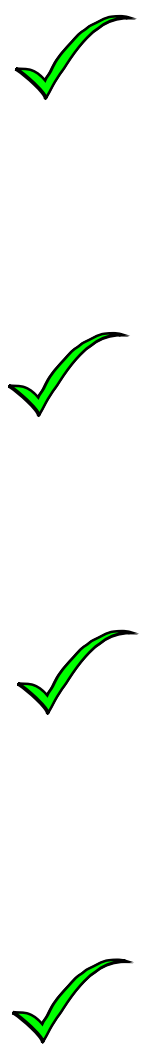

Figure 10. Summary of experimental results observed in this study. The left column indicates a cross section of the retina, whereas the middle column indicates a view of an intact retina within the planes of the inner nuclear and RGC layers. The right column indicates whether or not the indicated pattern was observed in this study. $\boldsymbol{A}$, The expected transsynaptic viral transmission pattern of ON-OFF-DSGCs to SACs. Both ON- and OFF-SACs would be expected to be labeled, as was observed. B, Nonsynaptic viral transmission from ON-OFF-DSGCs would be expected to label SACs with dendritic arbors not overlapping that of the DSGC, which was not observed. In addition, SAC-to-SAC transmission might have created this pattern, but again, this was not seen. $C-F$, Viral transmission from other RGC classes. C, ON-DSGCS, which are known to receive synaptic input from ON-SACS, transmitted to ON-SACs. Transmission was also seen to 0 FF-SACs by ON-DSGCS. D, E, OFF- $\alpha$-RGCs transmitted virus to OFF-SACS (D), while ON- $\alpha$-RGCs transmitted virus to ON-SACs (E). $\boldsymbol{F}, 0$ FF-DSGCS, both asymmetric and symmetric, also transmitted virus to both $\mathrm{ON}$ and OFF-SACS. 
the downstream partners of a single, molecularly defined cell type: SACs. Transgenic mouse lines expressing GFP in one or a small number of RGCs, and markers of specific cell types, have greatly aided the identification of specific RGCs by their anatomy. Physiology and patterns of central projections also have increased our understanding of RGC types. However, these methods do not allow systematic predictions about cell-cell connectivity patterns. Indeed, for some cell types, proximity among dendritic processes is not predictive of connectivity (Fig. 10). VSV tracing provides a powerful way to probe connectivity of RGCs, or other cell types, and suggests specific analyses that can be done using physiological methods to confirm and extend the observations made using viral tracing.

\section{VSV tracing of synaptically connected cell types}

A well characterized set of neurons with an established connection, SACs and DSGCs, were chosen to test the specificity of VSV transmission. Indeed, DSGCs were the most numerous types of RGCs that transmitted virus to SACs. The working model for ON-OFF-DSGC-SAC connectivity, based on EM reconstruction, suggests that synapses are distributed throughout the DSGC dendritic arbor, but the direction of connected SAC dendrites is asymmetrical; the soma-dendrite vector of most connected SACs points in the null direction of the DSGC (Briggman et al., 2011). Thus, connected SAC dendrites primarily arise from SAC somata that lie within the null side of the DSGC dendritic tree or just beyond this side of the tree (Wei et al., 2011). Here, viral transmission showed that infected SAC somata were distributed asymmetrically relative to the DSGCs (Fig. 6), consistent with the EM data and with electrophysiology (Lee et al., 2010; Briggman et al., 2011). We were not able to verify the preferred direction of labeled DSGCs but assume that the preferred direction pointed toward the cluster of labeled SACs. Furthermore, we found that OFF-DSGCs, too, were connected to SACs within their dendritic fields, and also showed an asymmetric distribution of the connected SAC somata (Fig. $7 D-G$ ). This is surprising given that OFF-DSGCs do not obviously stratify directly within ON- or OFF-SAC laminae (Kim et al., 2008). Finally, we found evidence for connections between SACs and $\alpha$-RGCs. These findings are supported by the proximity of genetically identified $\alpha$-RGC dendritic arbors (Fig. 8) and by direct stimulation and recordings from SACs and $\alpha$-RGCs, respectively (Fig. 9).

We found no evidence for SAC-to-SAC transmission (Fig. 10). This was surprising because the virus was replicationcompetent, and SACs have extensive dendritic overlap (coverage factor, 20-70) (Tauchi and Masland, 1984) and make reciprocal GABAergic synapses with each other (Lee and Zhou, 2006) (Fig. $9 B$ ). Perhaps either the viral glycoprotein or TVA was not available at the connections among SACs. SACs lack conventional axons or dendrites, which may prevent the viral glycoprotein from targeting their processes, thus precluding the budding of infectious virus. This result underscores the tight control of viral transmission but also shows that some specific connections may not be traced.

\section{Synaptic specificity}

Our data strongly suggest that transmission between RGCs and SACs was restricted to synapses. Two alternative possibilities for nonsynaptic transmission are not supported by the data: transmission between closely juxtaposed membranes among nonsynaptically connected cells; and transmission among cells that do not have overlapping processes. First, dendritic arbors of infected SACs always lay within the arbor of a transmitting RGC, and, in the case of DSGCs, the SAC somata were not randomly distributed but were clustered to one side as expected. However, there are hundreds of SACs that are not connected whose dendrites are distributed throughout the arbor of an ON-OFF-DSGC, which would have given a random distribution if they had been infected. These observations argue against a mechanism whereby virus released by an infected cell transmitted to cells with membrane overlap that were not connected. We also considered the possibility that, as cells became sick and died, virus might have been released nonspecifically. If this occurred, then one would expect the rate of nonsynaptic infection to increase over time, particularly at $>4$ dpi when cell morbidity was apparent. We did not observe this (Fig. 5D).

Viral transmission was selective for specific RGC types. There were 91 small-arbor RGCs, none of which transmitted virus to SACs, whereas several types of RGCs that occurred far less frequently transmitted at rates of $15-48 \%$. Calculations showed that the lack of transmission from small-arbor cells cannot be explained by a relatively small surface area for virus release and nonsynaptic transmission. We estimated the total surface area of the 91 small-arbor cells relative to an $\alpha$-RGC, based on the diameter of their respective arbors. We assumed that each small-arbor cell has approximately one-sixth the surface area of an $\alpha$-cell, assuming the small-arbor cell is monostratified; however, some of these cells were not monostratified, and therefore our calculation provides a conservative estimate. If 6 of 19 OFF- $\alpha$-RGCs transmitted to SACs, then of 91 small-arbor RGCs, $\sim 6$ of which are equivalent to $1 \alpha$-RGC in area, we would expect $\sim 5$ smallarbor cells to have transmitted. However, no transmission was seen from these 91 cells.

Together, the labeling patterns observed here between specific types of RGCs and SACs indicate that VSV transmission was restricted to direct synaptic connections.

\section{Transmission efficiency}

The average number of SACs infected by transmission from ONOFF-DSGCs was about four to five at $2 \mathrm{dpi}$. This is a small fraction of the estimated 200 SACs connected to each ON-OFF-DSGC, predicted from EM studies (Briggman et al., 2011). Thus, the efficiency of transmission by rVSV from ON-OFF-DSGCs to SACs is $\sim 2-3 \%$, similar to the reported efficiency of RABV transmission in cortex (5-10\%) (Marshel et al., 2010). Lack of complete labeling by these viruses is not surprising due to viral toxicity, which limits the window of time for spread, as well as the apparently high degree of specificity in transmission.

\section{VSV tracing revealed novel synaptic partners between SACs and identified RGC types}

Viral tracing provided evidence for novel SAC connectivity from $\sim 25 \%$ of all transmission events. In addition to the expected ONOFF and ON-DSGC transmission to SACs, we found connectivity also between SACs and ON- and OFF- $\alpha$-RGCs and OFF-DSGCs. We tested further the connection between SACs and $\alpha$-RGCs by making direct measurements, using optogenetics and whole-cell electrophysiology from large cell bodies. We found that SACs connect functionally to RGCs (both ON- $\alpha$ and OFF- $\alpha$, as well as OFF- $\delta$ ), and that these connections were cholinergic. Thus, in addition to their known cholinergic and GABAergic connections with DSGCs, SACs make cholinergic connections with $\alpha$-cells (Wässle et al., 1986; Schmidt et al., 1987; Vardi et al., 1989; Cohen et al., 1994). The connection between SACs and OFF $\delta$-cells, determined by physiology, could not be adequately tested by viral 
transmission due to the rarity of labeling $\delta$-cells following LGN injection.

VSV tracing provided evidence for novel connections between cell types that stratify in different layers but whose dendrites intersect. These vertical connections act in addition to the predominantly horizontal organization of the IPL and included ON-DSGC connections to OFF-SACs, and OFF-DSGCs to both ON and OFF-SACs. While these cells do not extensively costratify, previous studies have suggested possible synaptic connections (Sun et al., 2006; Kim et al., 2008) and our results further support this. The vectors of the connected SAC dendrites relative to those of the OFF-DSGC would need to be determined to discover whether they showed the same pattern as the null-side SACs described for the ONOFF-DSGCs (Briggman et al., 2011). If they did, it would provide a parsimonious mechanism for asymmetry of SAC-DSGC connections playing a role in establishing directional specificity to all retinal DSGCs.

Our data show that SACs contribute to multiple circuits beyond the expected DS types. Perhaps the wide-field cells receive SAC input because they play a role in detecting motion without being DS; this would predict symmetrical connections, something one could test in a larger data set or with more frequent viral transmission. However, the excitatory current in these cells, evoked by contrast, can be $10 \times$ larger (500-1000 pA) than the current evoked in the ChR2 experiment (50-100 pA) (Murphy and Rieke, 2006; van Wyk et al., 2009). Thus, the acetylcholine input apparently complements glutamate release from bipolar cells.

\section{Summary}

A protocol that uses rVSV pseudotyped with one envelope protein, and genetically encoding another, allows one to map, at single-cell resolution, connections within particular circuits. This method allows one to designate a starter population of neurons through the choice of the injection site, without the need to specify this population through genetic means. One can then use genetics to drive expression of the viral receptor, TVA, in specific presynaptic partners to be interrogated for connections with the starter cells. This method was used to map known and novel connections between retinal SACs and RGCs.

\section{References}

Barlow HB, Hill RM (1963) Selective sensitivity to direction of movement in ganglion cells of the rabbit retina. Science 139:412-414. CrossRef Medline

Beier KT, Samson ME, Matsuda T, Cepko CL (2011a) Conditional expression of the TVA receptor allows clonal analysis of descendents from Creexpressing progenitor cells. Dev Biol 353:309-320. CrossRef Medline

Beier KT, Saunders A, Oldenburg IA, Miyamichi K, Akhtar N, Luo L, Whelan SP, Sabatini B, Cepko CL (2011b) Anterograde or retrograde transsynaptic labeling of CNS neurons with vesicular stomatitis virus vectors. Proc Natl Acad Sci U S A 108:15414-15419. CrossRef Medline

Borghuis BG, Tian L, Xu Y, Nikonov SS, Vardi N, Zemelman BV, Looger LL (2011) Imaging light responses of targeted neuron populations in the rodent retina. J Neurosci 31:2855-2867. CrossRef Medline

Briggman KL, Helmstaedter M, Denk W (2011) Wiring specificity in the direction-selectivity circuit of the retina. Nature 471:183-188. CrossRef Medline

Chandran K, Sullivan NJ, Felbor U, Whelan SP, Cunningham JM (2005) Endosomal proteolysis of the Ebola virus glycoprotein is necessary for infection. Science 308:1643-1645. CrossRef Medline

Chklovskii DB (2004) Synaptic connectivity and neuronal morphology: two sides of the same coin. Neuron 43:609-617. CrossRef Medline

Cohen ED, Zhou ZJ, Fain GL (1994) Ligand-gated currents of alpha and beta ganglion cells in the cat retinal slice. J Neurophysiol 72:1260-1269. Medline
Demb JB (2007) Cellular mechanisms for direction selectivity in the retina. Neuron 55:179-186. CrossRef Medline

Demb JB, Singer JH (2012) Intrinsic properties and functional circuitry of the AII amacrine cell. Vis Neurosci 29:51-60. CrossRef Medline

Efron B, Tibshirani RJ (1993) An introduction to the bootstrap. London: Chapman and Hall.

Estevez ME, Fogerson PM, Ilardi MC, Borghuis BG, Chan E, Weng S, Auferkorte ON, Demb JB, Berson DM (2012) Form and function of the M4 cell, an intrinsically photosensitive retinal ganglion cell type contributing to geniculocortical vision. J Neurosci 32:13608-13620. CrossRef Medline

Euler T, Detwiler PB, Denk W (2002) Directionally selective calcium signals in dendrites of starburst amacrine cells. Nature 418:845-852. CrossRef Medline

Feller MB, Wellis DP, Stellwagen D, Werblin FS, Shatz CJ (1996) Requirement for cholinergic synaptic transmission in the propagation of spontaneous retinal waves. Science 272:1182-1187. CrossRef Medline

Freund TF, Martin KA, Smith AD, Somogyi P (1983) Glutamate decarboxylase-immunoreactive terminals of Golgi-impregnated axoaxonic cells and of presumed basket cells in synaptic contact with pyramidal neurons of the cat's visual cortex. J Comp Neurol 221:263-278. CrossRef Medline

Fried SI, Münch TA, Werblin FS (2002) Mechanisms and circuitry underlying directional selectivity in the retina. Nature 420:411-414. CrossRef Medline

Fried SI, Münch TA, Werblin FS (2005) Directional selectivity is formed at multiple levels by laterally offset inhibition in the rabbit retina. Neuron 46:117-127. CrossRef Medline

Gong S, Zheng C, Doughty ML, Losos K, Didkovsky N, Schambra UB, Nowak NJ, Joyner A, Leblanc G, Hatten ME, Heintz N (2003) A gene expression atlas of the central nervous system based on bacterial artificial chromosomes. Nature 425:917-925. CrossRef Medline

Hippenmeyer S, Vrieseling E, Sigrist M, Portmann T, Laengle C, Ladle DR, Arber S (2005) A developmental switch in the response of DRG neurons to ETS transcription factor signaling. PLoS Biol 3:e159. CrossRef Medline

Huberman AD, Manu M, Koch SM, Susman MW, Lutz AB, Ullian EM, Baccus SA, Barres BA (2008) Architecture and activity-mediated refinement of axonal projections from a mosaic of genetically identified retinal ganglion cells. Neuron 59:425-438. CrossRef Medline

Huberman AD, Wei W, Elstrott J, Stafford BK, Feller MB, Barres BA (2009) Genetic identification of an On-Off direction-selective retinal ganglion cell subtype reveals a layer-specific subcortical map of posterior motion. Neuron 62:327-334. CrossRef Medline

Ikeda H, Sheardown MJ (1982) Acetylcholine may be an excitatory transmitter mediating visual excitation of "transient" cells with the periphery effect in the cat retina: iontophoretic studies in vivo. Neuroscience 7:1299-1308. CrossRef Medline

Jacoby R, Stafford D, Kouyama N, Marshak D (1996) Synaptic inputs to ON parasol ganglion cells in the primate retina. J Neurosci 16:80418056. Medline

Kandel EJ (2000) Principles of neural science, Ed 4. New York: McGrawHill.

Kawaguchi Y, Kubota Y (1997) GABAergic cell subtypes and their synaptic connections in rat frontal cortex. Cereb Cortex 7:476-486. CrossRef Medline

Kay JN, De la Huerta I, Kim IJ, Zhang Y, Yamagata M, Chu MW, Meister M, Sanes JR (2011) Retinal ganglion cells with distinct directional preferences differ in molecular identity, structure, and central projections. J Neurosci 31:7753-7762. CrossRef Medline

Kim IJ, Zhang Y, Yamagata M, Meister M, Sanes JR (2008) Molecular identification of a retinal cell type that responds to upward motion. Nature 452:478-482. CrossRef Medline

Kim IJ, Zhang Y, Meister M, Sanes JR (2010) Laminar restriction of retinal ganglion cell dendrites and axons: subtype-specific developmental patterns revealed with transgenic markers. J Neurosci 30:1452-1462. CrossRef Medline

Knipe DM (2007) Fields virology. Philadelphia: Lippincott Williams and Wilkins.

Kolb H, Famiglietti EV (1974) Rod and cone pathways in the inner plexiform layer of cat retina. Science 186:47-49. CrossRef Medline

Lee S, Zhou ZJ (2006) The synaptic mechanism of direction selectivity in distal processes of starburst amacrine cells. Neuron 51:787-799. CrossRef Medline 
Lee S, Kim K, Zhou ZJ (2010) Role of Ach-GABA cotransmission in detecting image motion and motion direction. Neuron 68:1159-1172. CrossRef Medline

Lewandoski M, Martin GR (1997) Cre-mediated chromosome loss in mice. Nat Genet 17:223-225. CrossRef Medline

Madisen L, Zwingman TA, Sunkin SM, Oh SW, Zariwala HA, Gu H, Ng LL, Palmiter RD, Hawrylycz MJ, Jones AR, Lein ES, Zeng H (2010) A robust and high-throughput Cre reporting and characterization system for the whole mouse brain. Nat Neurosci 13:133-140. CrossRef Medline

Manookin MB, Beaudoin DL, Ernst ZR, Flagel LJ, Demb JB (2008) Disinhibition combines with excitation to extend the operating range of the OFF visual pathway in daylight. J Neurosci 28:4136-4150. CrossRef Medline

Manookin MB, Weick M, Stafford BK, Demb JB (2010) NMDA receptor contributions to visual contrast coding. Neuron 67:280-293. CrossRef Medline

Margolis DJ, Detwiler PB (2007) Different mechanisms generate maintained activity in ON and OFF retinal ganglion cells. J Neurosci 27:59946005. CrossRef Medline

Marshel JH, Mori T, Nielsen KJ, Callaway EM (2010) Targeting single neuronal networks for gene expression and cell labeling in vivo. Neuron 67:562-574. CrossRef Medline

Mathie A, Colquhoun D, Cull-Candy SG (1990) Rectification of currents activated by nicotinic acetylcholine receptors in rat sympathetic ganglion neurones. J Physiol 427:625-655. Medline

Miyamichi K, Amat F, Moussavi F, Wang C, Wickersham I, Wall NR, Taniguchi H, Tasic B, Huang ZJ, He Z, Callaway EM, Horowitz MA, Luo L (2011) Cortical representations of olfactory input by trans-synaptic tracing. Nature 472:191-196. CrossRef Medline

Murphy GJ, Rieke F (2006) Network variability limits stimulus-evoked spike timing precision in retinal ganglion cells. Neuron 52:511-524. CrossRef Medline

Narayan S, Barnard RJ, Young JA (2003) Two retroviral entry pathways distinguished by lipid raft association of the viral receptor and differences in viral infectivity. J Virol 77:1977-1983. CrossRef Medline

O’Donnell P, Lavín A, Enquist LW, Grace AA, Card JP (1997) Interconnected parallel circuits between rat nucleus accumbens and thalamus revealed by retrograde transynaptic transport of pseudorabies virus. J Neurosci 17:2143-2167. Medline

Osterhout JA, Josten N, Yamada J, Pan F, Wu SW, Nguyen PL, Panagiotakos G, Inoue YU, Egusa SF, Volgyi B, Inoue T, Bloomfield SA, Barres BA, Berson DM, Feldheim DA, Huberman AD (2011) Cadherin-6 mediates axon-target matching in a non-image-forming visual circuit. Neuron 71: 632-639. CrossRef Medline

Reiner A, Jiao Y, Del Mar N, Laverghetta AV, Lei WL (2003) Differential morphology of pyramidal tract-type and intratelencephalically projecting-type corticostriatal neurons and their intrastriatal terminals in rats. J Comp Neurol 457:420-440. CrossRef Medline

Rivlin-Etzion M, Zhou K, Wei W, Elstrott J, Nguyen PL, Barres BA, Huberman AD, Feller MB (2011) Transgenic mice reveal unexpected diversity of on-off direction-selective retinal ganglion cell subtypes and brain structures involved in motion processing. J Neurosci 31:8760-8769. CrossRef Medline

Rockhill RL, Daly FJ, MacNeil MA, Brown SP, Masland RH (2002) The diversity of ganglion cells in a mammalian retina. J Neurosci 22:38313843. Medline

Rodriguez Boulan E, Pendergast M (1980) Polarized distribution of viral envelope proteins in the plasma membrane of infected epithelial cells. Cell 20:45-54. CrossRef Medline

Schmidt M, Humphrey MF, Wässle H (1987) Action and localization of acetylcholine in the cat retina. J Neurophysiol 58:997-1015. Medline

Seidler B, Schmidt A, Mayr U, Nakhai H, Schmid RM, Schneider G, Saur D
(2008) A Cre-loxP-based mouse model for conditional somatic gene expression and knockdown in vivo by using avian retroviral vectors. Proc Natl Acad Sci U S A 105:10137-10142. CrossRef Medline

Siegert S, Scherf BG, Del Punta K, Didkovsky N, Heintz N, Roska B (2009) Genetic address book for retinal cell types. Nat Neurosci 12:1197-1204. CrossRef Medline

Straschill M, Perwein J (1973) The effect of iontophoretically applied acetylcholine upon the cat's retinal ganglion cells. Pflugers Arch 339:289298. CrossRef Medline

Sun W, Deng Q, Levick WR, He S (2006) ON direction-selective ganglion cells in the mouse retina. J Physiol 576:197-202. CrossRef Medline

Tauchi M, Masland RH (1984) The shape and arrangement of the cholinergic neurons in the rabbit retina. Proc R Soc Lond B Biol Sci 223:101119. CrossRef Medline

Thomas DC, Brewer CB, Roth MG (1993) Vesicular stomatitis virus glycoprotein contains a dominant cytoplasmic basolateral sorting signal critically dependent upon a tyrosine. J Biol Chem 268:3313-3320. Medline

van Wyk M, Wässle H, Taylor WR (2009) Receptive field properties of ONand OFF-ganglion cells in the mouse retina. Vis Neurosci 26:297-308. CrossRef Medline

Vaney DI, Pow DV (2000) The dendritic architecture of the cholinergic plexus in the rabbit retina: selective labeling by glycine accumulation in the presence of sarcosine. J Comp Neurol 421:1-13. CrossRef Medline

Vardi N, Masarachia PJ, Sterling P (1989) Structure of the starburst amacrine network in the cat retina and its association with alpha ganglion cells. J Comp Neurol 288:601-611. CrossRef Medline

Völgyi B, Chheda S, Bloomfield SA (2009) Tracer coupling patterns of the ganglion cell subtypes in the mouse retina. J Comp Neurol 512:664-687. CrossRef Medline

Wall NR, Wickersham IR, Cetin A, De La Parra M, Callaway EM (2010) Monosynaptic circuit tracing in vivo through Cre-dependent targeting and complementation of modified rabies virus. Proc Natl Acad Sci U S A 107:21848-21853. CrossRef Medline

Wässle H, Voigt T, Schmidt M, Humphrey M (1986) Action and localisation of neurotransmitters in the cat retina. Neurosci Res Suppl 4:S181S195. CrossRef Medline

Wei W, Feller MB (2011) Organization and development of directionselective circuits in the retina. Trends Neurosci 34:638-645. CrossRef Medline

Wei W, Hamby AM, Zhou K, Feller MB (2011) Development of asymmetric inhibition underlying direction selectivity in the retina. Nature 469:402406. CrossRef Medline

Whelan SP, Ball LA, Barr JN, Wertz GT (1995) Efficient recovery of infectious vesicular stomatitis virus entirely from cDNA clones. Proc Natl Acad Sci U S A 92:8388-8392. CrossRef Medline

Wickersham IR, Lyon DC, Barnard RJ, Mori T, Finke S, Conzelmann KK, Young JA, Callaway EM (2007) Monosynaptic restriction of transsynaptic tracing from single, genetically targeted neurons. Neuron 53:639647. CrossRef Medline

Wickersham IR, Sullivan HA, Seung HS (2010) Production of glycoproteindeleted rabies viruses for monosynaptic tracing and high-level gene expression in neurons. Nat Protoc 5:595-606. CrossRef Medline

Yazejian B, Fain GL (1993) Whole-cell currents activated at nicotinic acetylcholine receptors on ganglion cells isolated from goldfish retina. Vis Neurosci 10:353-361. CrossRef Medline

Yonehara K, Balint K, Noda M, Nagel G, Bamberg E, Roska B (2011) Spatially asymmetric reorganization of inhibition establishes a motionsensitive circuit. Nature 469:407-410. CrossRef Medline

Zhang J, Li W, Hoshi H, Mills SL, Massey SC (2005) Stratification of alpha ganglion cells and ON/OFF directionally selective ganglion cells in the rabbit retina. Vis Neurosci 22:535-549. Medline 